\title{
Driving Control Research for Longitudinal Dynamics of Electric Vehicles with Independently Driven Front and Rear Wheels
}

\author{
Wei Liu, Hongwen He, and Jiankun Peng \\ National Engineering Laboratory for Electric Vehicles, Beijing Institute of Technology, Beijing 100081, China \\ Correspondence should be addressed to Hongwen He; hwhebit@bit.edu.cn
}

Received 4 August 2013; Accepted 30 September 2013

Academic Editor: Claude Lamarque

Copyright ( 2013 Wei Liu et al. This is an open access article distributed under the Creative Commons Attribution License, which permits unrestricted use, distribution, and reproduction in any medium, provided the original work is properly cited.

\begin{abstract}
This paper takes the electric off-road vehicle with separated driven axles as the research object. To solve the longitudinal dynamics driving control problems, vehicle dynamics model, and control strategies were studied and the corresponding simulation was carried out. An 8-DOF vehicle dynamics model with separated driven axles was built. The driving control strategies on the typical roads were put forward. The recognition algorithm of the typical road surfaces based on the wheels' slip rates was proposed. And the two control systems were designed including the pedal opening degree adjustment control system based on PI algorithm and the interaxle torque distribution control system based on sliding mode control algorithm. The driving control flow of the proposed vehicle combining the pedal adjustment control system with the interaxle torque distribution control system was developed. And the driven control strategies for the typical roads were simulated. Simulation results show that the proposed drive control strategies can adapt to different typical road surfaces, limit the slip rates of the driving wheels within the stable zone, and ensure the vehicle driving safely and stably in accordance with the driver's intention.
\end{abstract}

\section{Introduction}

The deterioration problem of energy and environment makes the ecovehicles with motor driving develop rapidly. Several types of drive systems have been proposed for ecovehicles such as front- or rear-wheel-drive system with two in-wheel motors and four-wheel-drive system with independently driven front and rear motors or four in-wheel motors [1], among which the system with independently driven front and rear motors has shown many advantages in the power matching, driving control, regenerative braking, and space layout. The front and rear motors act independently and the torque response is fast and accurate, which provides broad prospects for improvement of vehicle performance. And the method to control the vehicle performance through the driving force can enrich the current TCS and ESP function, which will improve the vehicle stability and safety.

Control strategy is the key of traction control [2]. Interaxle torque distribution strategy has important influence on vehicle performance, which has been studied by many researchers [3-6]. Antislip control study of traditional vehicle has made great effect [7-11]. Mutoh et al. made a detailed analysis of the characteristics of electric vehicles with independently driven front and rear wheels [12]. Kang et al. designed a hierarchical control structure for the axle-separated-driven system, which effectively improved its maneuverability, lateral stability, and rollover prevention performance [13]. Zhao et al. studied antiskid driving control strategy for a four-wheel-drive hybrid car, which inhibited the instantaneous slip of driving wheel effectively [14]. However, the current control strategy for single road surface is incomplete and the antislip control for electric vehicles with axles separated driven system has some new characteristics.

Focusing on electric vehicles with independently driven front and rear wheels, taking an electric off-road vehicle as the research platform, combined with the antislip control for the four-wheel-drive vehicle, we studied the driving control strategies and algorithms for longitudinal dynamics to improve the dynamic performance and safety on different road surfaces. Based on the pedal adjustment control system and the interaxle torque distribution control system, the driving control flow, through which the driving control strategies can switch adaptively according to road surfaces, was proposed. And the driving control strategies for 


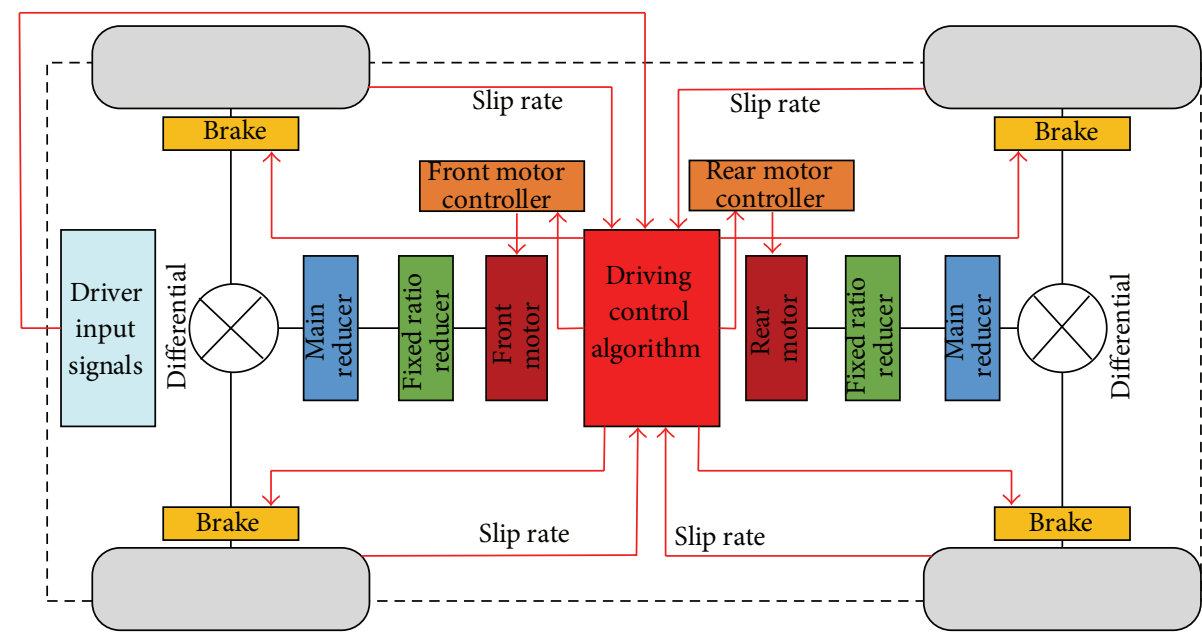

Figure 1: Powertrain system structure of an electric off-road vehicle.

different road surfaces were verified through the simulation.

\section{Vehicle Dynamics Modeling}

2.1. Powertrain Structure and Basic Parameters. The powertrain of an electric off-road vehicle with independently front and rear drive wheels is shown in Figure 1, and the front drive axle and the rear drive axle are independent and symmetric. They have the same parameters in pursuit of mass production. The front and rear motors pass their power through the fixed ratio reducer, the main reducer, differential and the wheel reducer, and in turn to the front and rear wheels.

The basic parameters of the vehicle are shown in Table 1.

2.2. Vehicle Dynamics Model. Using modular method, each part of the dynamic models of the vehicle is established as follows.

(1) Driver Model. The driver model imitates the driver's driving intention. It generates 5 signals as

$$
X_{\text {driver }}=\left\{A_{\mathrm{PS}}, B_{\mathrm{PS}}, S_{\mathrm{WA}}, L_{\mathrm{SH}}, L_{\mathrm{CL}}\right\}^{T} \text {, }
$$

where $A_{\mathrm{PS}}$ is the accelerator pedal signal, $B_{\mathrm{PS}}$ is the brake pedal signal, $S_{\mathrm{WA}}$ is the steering wheel angle, $L_{\mathrm{SH}}$ is the gear selection signal, and $L_{\mathrm{CL}}$ is the clutch pedal signal.

(2) Interaxle Torque Distribution Model. This model decides the electric opening degree of front and rear motors according to the outputs of the driver model and the driving control model, and the distribution relation is as follows:

$$
\begin{gathered}
T_{\text {desire }}=F_{D}\left(A_{\mathrm{ps}}-F_{B} B_{\mathrm{ps}}\right)\left(T_{f \max }+T_{r \max }\right), \\
K_{D f}=F_{T} \frac{T_{\text {desire }}}{T_{f \max }} \in[-1,1], \\
K_{D r}=\left(1-F_{T}\right) \frac{T_{\text {desire }}}{T_{r \max }} \in[-1,1],
\end{gathered}
$$

where $F_{B}$ is the proportion between motor brake and mechanical brake, $F_{D}$ is the pedal adjustment coefficient, $F_{T}$ is the distribution coefficient of the shaft torque, $T_{f \max }$ and $T_{r \text { max }}$ are the maximum torque at current speed of front and rear motor, respectively, and $T_{\text {desire }}$ is the driver torque request taking account of the pedal adjustment coefficient.

(3) Driving Motor Model. The permanent magnet synchronous motor can usually be modeled by space vector control method $[15,16]$. Here, the motor model generates driving/braking torque according to the inputs of the motor speed and motor desired torque percentage:

$$
T_{m}= \begin{cases}\frac{K_{D} P_{\max }}{n_{N}} \cdot \frac{1}{T^{2} s^{2}+2 T \xi s+1}, & 0 \leq n \leq n_{N}, \\ \frac{K_{D} P_{\max }}{n} \cdot \frac{1}{T^{2} s^{2}+2 T \xi s+1}, & n_{N}<n \leq n_{\max },\end{cases}
$$

where $K_{D}$ is the motor desired torque percentage corresponding to pedal signals, $n$ is the motor speed, $T$ and $\xi$ are the time constant and damping ratio of the two-order vibration system, respectively.

Figure 2(a) shows the drive torque and regenerative torque characteristic curve of the motor.

Take $\xi=0.3$ and $T=0.2 \mathrm{~s} / \mathrm{rad}$ according to engineering experiences. Figure 2(b) shows the torque step response under the condition of $K_{D}=1$ and $n=5000 \mathrm{rpm}$, where the maximum overshoot is $37.23 \%$ and the response time of the error within $\pm 5 \%$ is $0.2 \mathrm{~s}$, which fits the experiment results well.

(4) Transmission Model. The front and rear motors deliver their power through the fixed ratio reducer, the main reducer, and the differential and the wheel reducer, and in turn to the front and rear wheels, assuming the torque distributes 
TABLE 1: Basic parameters of the vehicle.

\begin{tabular}{|c|c|c|c|}
\hline Parameters & Symbols & Units & Values \\
\hline Gross mass & $m$ & $\mathrm{~kg}$ & 7000 \\
\hline Wheelbase (front, rear) & $\left(l_{f}, l_{r}\right)$ & $\mathrm{m}$ & $(2.262,1.638)$ \\
\hline Track width (front, rear) & $\left(d_{f}, d_{r}\right)$ & $\mathrm{m}$ & $(2.1,2.1)$ \\
\hline Centroid height & $h_{g}$ & $\mathrm{~m}$ & 0.9 \\
\hline Windward area & $A$ & $\mathrm{~m}^{2}$ & 3.9 \\
\hline Air drag coefficient & $C_{D}$ & - & 0.65 \\
\hline Wheel rolling radius & $R_{e}$ & $\mathrm{~m}$ & 0.450 \\
\hline Rolling resistance coefficient & $f_{r}$ & - & 0.015 \\
\hline Wheel rotational inertia & $I_{W}$ & $\mathrm{~kg} \cdot \mathrm{m}^{2}$ & 1.25 \\
\hline Rotary mass coefficient & $\delta$ & - & 1.1794 \\
\hline Fixed reducer ratio & $i_{g}$ & - & 3.36 \\
\hline Main reducer ratio & $i_{0}$ & - & 4.9152 \\
\hline Efficiency of transmission & $\eta_{T}$ & - & 0.9 \\
\hline Motor peak/rated power & $P_{\max } / P_{N}$ & $\mathrm{~kW}$ & $90 / 45$ \\
\hline Motor maximum/rated speed & $n_{\max } / n_{N}$ & rpm & $6000 / 2000$ \\
\hline Motor peak/rated torque & $T_{\max } / T_{N}$ & $\mathrm{~N} \cdot \mathrm{m}$ & $430 / 215$ \\
\hline
\end{tabular}

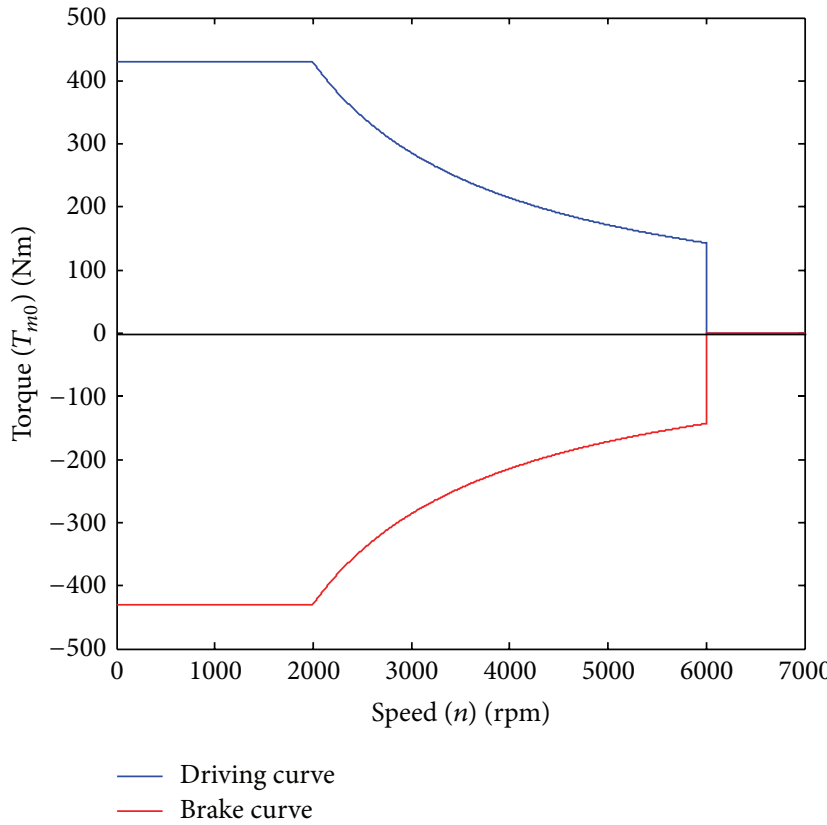

(a)

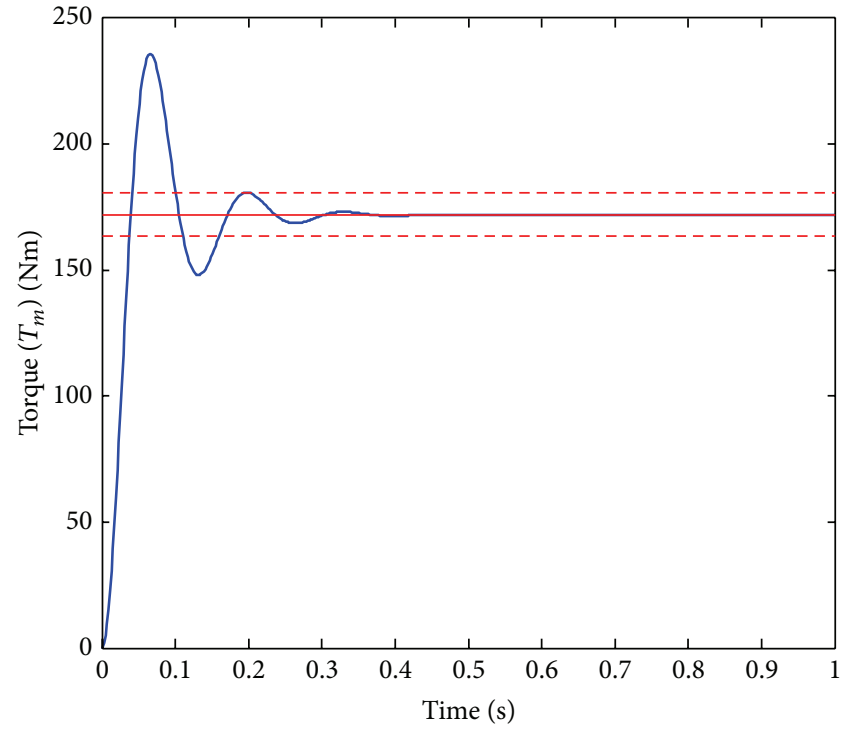

(b)

FIGURE 2: The static and dynamic characteristics of the motor: (a) static drive torque and regenerative torque characteristic; (b) torque step response of the motor.

equally among left and right driving axle. The equation of the transmission system can be expressed as

$$
\begin{gathered}
T_{0}=T_{m} \eta i_{g} i_{0}-\left(I_{0}+I_{g} i_{0}^{2}\right) \dot{\omega}_{0}, \\
T_{\mathrm{Wl}}=T_{\mathrm{Wr}}=\frac{T_{0}}{2}, \\
\dot{\omega}_{0}=\frac{\dot{\omega}_{\mathrm{Wl}}+\dot{\omega}_{\mathrm{Wr}}}{2},
\end{gathered}
$$

where $T_{0}, T_{\mathrm{Wl}}$, and $T_{\mathrm{Wr}}$ are the torques output of the main reducer and the left and right wheels, respectively, $\dot{\omega}_{0}, \dot{\omega}_{\mathrm{Wl}}$, and $\dot{\omega}_{\mathrm{Wr}}$ are the angular acceleration of the output of main reducer and the left and right wheels, respectively, $I_{0}$ and $I_{g}$ are the equivalent moment of inertias of the main reducer and the reducer.
(5) Wheel Model

$$
I_{W} \dot{\omega}_{W}=T_{W}-T_{b}-F_{x} R_{e}-f_{r} F_{z} R_{e}
$$


TABLE 2: Tire parameters based on "Magic Formula."

\begin{tabular}{lccccccccc}
\hline & 0 & 1 & 2 & 3 & 4 & 5 & 6 & 7 & 8 \\
\hline${ }^{*} a_{i}$ & 1.374 & -0.2501 & -980.0 & -1845 & 10.80 & -0.0110 & -0.0295 & 0.4052 & 0.0207 \\
${ }^{*} b_{i}$ & 1.5 & -2.4 & 1050 & 20 & 226 & 0.069 & -0.006 & 0.056 & 0.486 \\
${ }^{*} c_{i}$ & 2.34 & -0.9250 & -6.417 & 2.004 & 0.0577 & 0.0984 & 0.0028 & -0.0100 & 0.0100 \\
\hline & 9 & 10 & 11 & 12 & 13 & 14 & 15 & 16 \\
\hline${ }^{*} a_{i}$ & 0 & 0 & -14.24 & 0 & 0 & - & - & - \\
${ }^{*} b_{i}$ & 0 & 0 & - & - & - & - & - & - \\
${ }^{*} c_{i}$ & -3.000 & 0.0255 & 0.0036 & 0.0103 & -0.0647 & -0.0111 & -0.3947 & -0.0994 \\
\hline
\end{tabular}

${ }^{*} a_{i}, b_{i}$, and $c_{i}$ are the tire parameters required to solve the lateral, longitudinal, and aligning torque tire force, respectively, in the "Magic Formula" developed by Pacejka and Bakker $[17,18]$.

where $T_{b}$ is the braking torque, $\dot{\omega}_{W}$ is the wheel angular acceleration, $F_{Z}$ is the wheel vertical load, and $F_{x}$ is the longitudinal tire force.

(6) Tire Model. The tire dynamics are usually modeled with the "Magic Formula" developed by Pacejka and Bakker [17, 18]. In this model, the tire force is described as the complex nonlinear function of the tire vertical load, slip rate, and slip angle. Considering tire longitudinal force, lateral force, and aligning torque the "magic formula" mathematical model is as follows:

$$
\begin{gathered}
F=D \sin [C \arctan \{B X-E(B X-\arctan (B X))\}]+S_{v}, \\
X=x+S_{h}, \\
F_{x}=\frac{\left|\sigma_{x}\right|}{\sigma} F_{x 0}, \quad F_{y}=\frac{\left|\sigma_{y}\right|}{\sigma} F_{y 0}, \\
\sigma_{x}=-\frac{s}{s+1}, \quad \sigma_{y}=-\frac{\tan \alpha}{s+1}, \quad \sigma=\sqrt{\sigma_{x}^{2}+\sigma_{y}^{2}},
\end{gathered}
$$

where $B, C, D, E, S_{v}$, and $S_{h}$ are the stiffness, shape, peak, curvature, horizontal drift, and vertical drift factor, respectively. All of them are described as the function of the tire vertical load, tire slip rate, and tire slip angle. The tire model parameters used in this paper are shown in Table 2.

(7) Brake Model. In pure electric vehicles, the brake comprises the regenerative braking and the mechanical braking, and the regenerative braking is controlled by the motor module. The following is mechanical brake model's equation:

$$
T_{b}=K_{b e} A_{b} R_{b e} P,
$$

where $K_{b e}$ is the braking efficacy factor, $A_{b}$ is the crosssectional area of the brake cylinder, $R_{b e}$ is the equivalent radius, and $P$ is the braking pressure.

(8) Steering Model. The simplified steering system model was established by modifying a one order inertial link:

$$
\delta_{f}=\frac{S_{\mathrm{WA}}}{i_{\mathrm{sW}}\left(T_{f} s+1\right)}, \quad-\delta_{s \max } \leq \delta_{s} \leq \delta_{s \max },
$$

where $\delta_{f}$ is the steering angles of front wheels, $i_{\text {sw }}$ is the transmission ratio from the steering wheel to the front wheels, $S_{\mathrm{WA}}$ is the steering wheel angle, $\delta_{s \max }$ is the limit of the steering, angle $T_{f}$ is the time constant of the one order inertia link.

(9) Road Input Model. The road inputs at each wheel are independent. Without considering the random change of surface elevation, this paper used a vector containing three pavement characteristic parameters to represent the road condition:

$$
x_{\mathrm{Road}}=\left\{f_{s}, f_{r}, \alpha\right\}^{T},
$$

where $f_{s}$ is the road adhesion coefficient and $\alpha$ is the road gradient.

(10) Vehicle Body Model. Here the vehicle body model includes the longitudinal, lateral displacement and the yaw angle displacement:

$$
\begin{gathered}
\begin{aligned}
m\left(a_{x}-v_{y} \frac{d \gamma}{d t}\right)= & F_{x r l}+F_{x r r}+\left(F_{x f l}+F_{x f r}\right) \cos \delta_{f} \\
& -\left(F_{y f l}+F_{y f r}\right) \sin \delta_{f}-\frac{C_{D} A u_{x}^{2}}{21.15} \\
& -m g \sin \alpha, \\
m\left(a_{y}+v_{x} \frac{d \gamma}{d t}\right)= & F_{y r l}+F_{y r r}+\left(F_{x f l}+F_{x f r}\right) \sin \delta_{f} \\
& +\left(F_{y f l}+F_{y f r}\right) \cos \delta_{f}, \\
I_{z} \frac{d^{2} \gamma}{d t^{2}}= & l_{f}\left[\left(F_{x f l}+F_{x f r}\right) \sin \delta_{f}+\left(F_{y f l}+F_{y f r}\right) \cos \delta_{f}\right] \\
+ & \frac{d_{f}}{2}\left[\left(F_{x f r}-F_{x f l}\right) \cos \delta_{f}+\left(F_{y f l}-F_{y f r}\right) \sin \delta_{f}\right] \\
+ & \frac{d_{r}}{2}\left(F_{x r r}-F_{x r l}\right)-l_{r}\left(F_{y r l}+F_{y r r}\right),
\end{aligned}
\end{gathered}
$$

where $F_{x i}, F_{y i}(i=f l, f r, r l, r r)$ are the longitudinal and lateral force of each tire, $u_{x}$ is the longitudinal velocity of the vehicle in $\mathrm{km} / \mathrm{h}, \gamma$ is the yaw displacement of the vehicle body, $v_{x}, v_{y}$ are the longitudinal and lateral velocities of the 


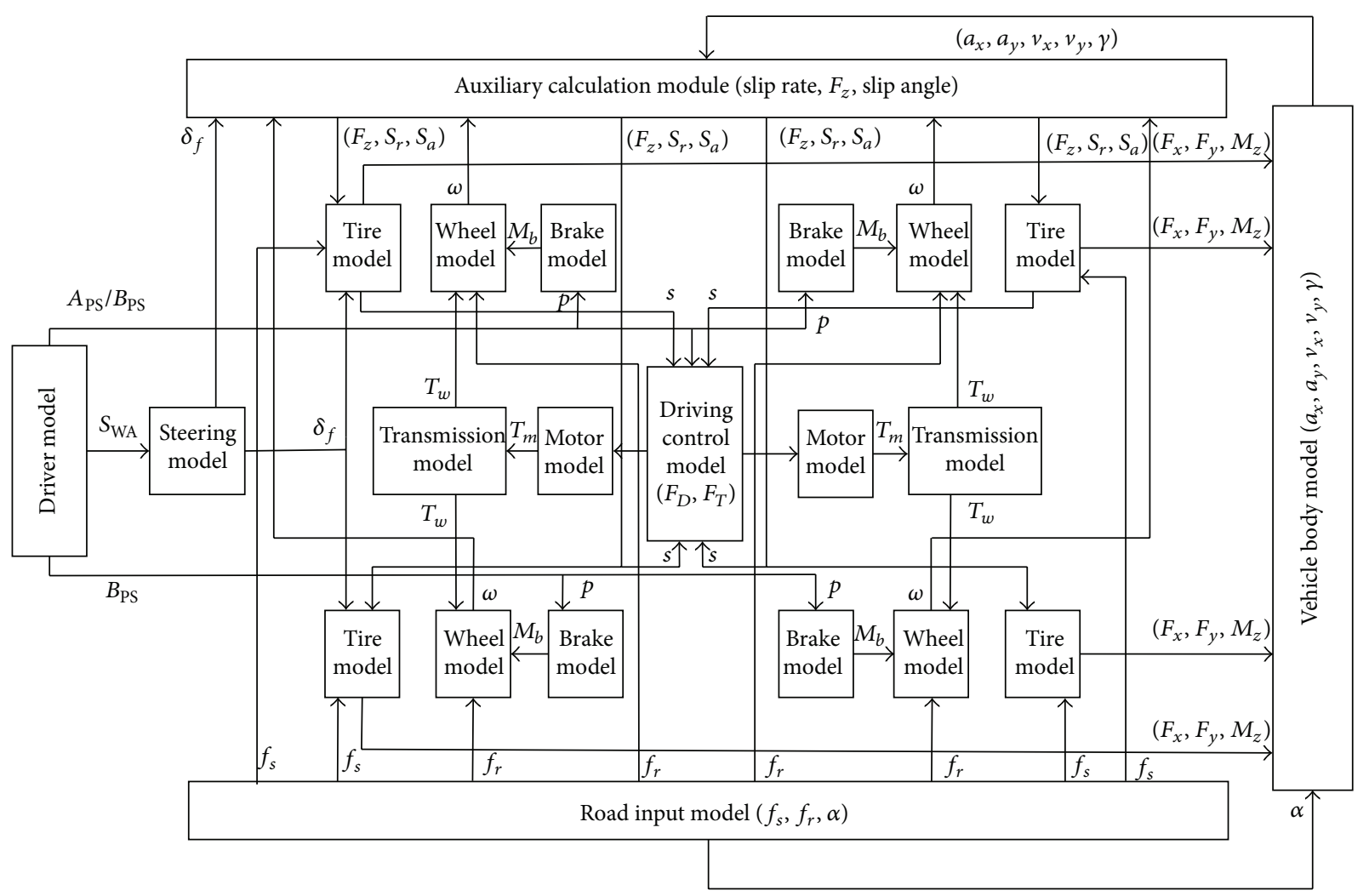

FIGURE 3: Overall structure of the vehicle system dynamics model.

vehicle, respectively and $a_{x}, a_{y}$ are the longitudinal and lateral accelerations, respectively.

(11) Calculation Module. This module estimates the vehicle state parameters and calculates and returns the speeds or angular accelerations of each part of the transmission, to help forming the closed loop frame of the vehicle dynamics model.

(12) Driving Control Model. This paper mainly studied the control strategies on driving condition, involving the pedal adjustment coefficient that is $F_{D}$ and the torque distribution coefficient between axes that are $F_{T}$. The decision variables are

$$
X_{d e}^{*}=\left\{F_{D}, F_{T}\right\}^{T} \text {. }
$$

The driving control strategy and algorithm of the decision variables, that is, $F_{D}, F_{T}$, are key points of this paper, which will be discussed in detail in Section 3 .

2.3. Overall Structure of the Dynamics Model. The 8DOF vehicle dynamics model established in this paper included the longitudinal, lateral, and yaw displacements of the body, the rotational displacements of the four independent wheels, and the steering angle displacement of the front wheels, with the assumption that the two front wheels had the same steering angle and there was no rubbing effect in the differential mechanism. Using the dynamic models established above, the dynamics model of the vehicle with independently driven front and rear wheels was built as shown in Figure 3.

In Figure $3, s_{r}, s_{a}$ are the slip rate and the side slip angle of the wheels, respectively.

\section{Driving Control Strategy and Algorithm}

3.1. Driving Control Strategies on Different Typical Surfaces. This paper mainly studied the control strategies on driving condition, involving the two decision variables, namely, $F_{D}$ and $F_{T}$. The strategies on different typical road surfaces were designed as follows.

(1) High Adhesion Road. When driving on high adhesion road, the road adhesion coefficient at each driving wheel is large enough, as the reverse torque the road can provide, namely, $T_{\text {road }}$, is greater than maximum driving torque $T_{\max }$, that is, $T_{\text {desire }} \leq T_{\max } \leq T_{\text {road }}$, where $T_{\max }=T_{f \max }+T_{r \text { max }}$. At the whole range of the accelerator pedal, the slip ratio keeps in stable slip zone, namely, below peak slip rate $\lambda_{\text {opt }}$. There is no need to adjust the acceleration pedal angle signal, so that the pedal adjustment coefficient is constant 1, known as the "fixed pedal adjustment coefficient model." In addition, the torque distribution coefficient is decided according to the static axle load distribution proportion, namely, $F_{T}=l_{r} /\left(l_{f}+l_{r}\right)$, which is called the "fixed proportion distribution model." 
The fixed pedal adjustment coefficient and fixed torque distribution coefficient are the initial values of the two decision variables at the same time, namely:

$$
\begin{gathered}
F_{D 0}=1, \\
F_{T 0}=\frac{l_{r}}{\left(l_{f}+l_{r}\right)} .
\end{gathered}
$$

(2) Low Adhesion Uniform Road. When driving on low adhesion uniform road, the road adhesion coefficient at each driving wheel is close but not large enough, as the reverse torque the road can provide is smaller than the maximum driving torque, that is, $T_{\text {road }} \leq T_{\max }$. When the accelerator pedal is in elevation range, that is, $T_{\text {road }} \leq T_{\text {desire }} \leq T_{\max }$, the road adhesion cannot meet the driver's torque request, so the slip rate of driving wheel will be in the unstable region, namely, $\lambda_{\text {opt }} \leq \lambda \leq 1$. In this case, the pedal adjustment coefficient should be reduced to make the slip rated back to stable zone and close to $\lambda_{\text {opt }}$ with the purpose of making the road adhesion ability into full play and meeting the driver's torque request as far as possible. In addition, the "fixed proportion distribution model" is adopted as the road adhesion conditions at front and rear are similar.

(3) Bisectional Road. Bisectional road refers to such pavement whose adhesion conditions at left side and right side are different significantly. When driving on this surface, the wheel at low friction side will slip seriously, the slip rate at left and right side will differ a lot. The driving wheels at the left and right side generate driving forces with the same slip rate, and the adhesive ability of both sides is not fully utilized. The driving control strategy does not adopt differential locking control or braking torque control to avoid the yaw motion, and the strategy should make full use of the adhesive ability of the low friction side to guarantee the longitudinal dynamic or through performance. By reducing the pedal adjustment coefficient, make the wheel slip rate of the low friction side back to stable zone and close to $\lambda_{\text {opt }}$, to meet the driver's torque request as far as possible with no yaw motion generated. As the road adhesion conditions at front and rear are similar, the "fixed proportion distribution model" is still adopted.

(4) Joint Road. Joint road refers to such road whose road adhesion performs a step change, for instance, when driving from the high adhesion road to the low adhesion road or vice versa. When driving on this surface, the wheel at low adhesion will slip seriously, and the slip rate at front and rear end will differ a lot. In this case, the interaxle torque distribution control should be activated. The driving torque proportion at the low adhesion should be reduced and the high adhesion should be enlarged, to make the slip rate at low adhesion lower and the high friction higher. When the slip rate difference between front and rear axles is reduced to a reasonable level, the strategy should judge whether the slip rates are within stable zone; if yes, the "fixed pedal adjustment coefficient model" will be adopted; if no, the pedal adjustment control will be activated, to make the average slip rate of the
TABLE 3: Driving strategies on different typical surfaces.

\begin{tabular}{lc}
\hline Typical surfaces & Driving control strategies \\
\hline High & $F_{D 0}=1, F_{T 0}=l_{r} /\left(l_{f}+l_{r}\right)$ \\
Low and uniform & Pedal adjustment control, \\
& $F_{T 0}=l_{r} /\left(l_{f}+l_{r}\right)$ \\
Bisectional & Pedal adjustment control, \\
& $F_{T 0}=l_{r} /\left(l_{f}+l_{r}\right)$ \\
Joint & Pedal adjustment control, torque \\
& distribution control \\
\hline
\end{tabular}

wheels back into stable zone and close to $\lambda_{\text {opt }}$, in order to meet the driver's torque demand as far as possible.

In summary, the driving strategies on different typical road surfaces were designed as shown in Table 3.

\subsection{The Typical Surfaces' Recognition Algorithm Based on Slip}

Rate. The driving control system needs to judge the vehicle driving conditions real-timely according to the four wheels' slip rates, namely $\left(S_{f l}, S_{f r}, S_{r l}, S_{r r}\right)$, to provide a basis for the selections of pedal adjustment control modes and the interaxle torque distribution control modes.

In order to facilitate the recognition, the mean of the slip rates was calculated as follows:

$$
\begin{aligned}
& S_{\text {front }}=\frac{S_{f l}+S_{f r}}{2} ; \quad S_{\text {rear }}=\frac{S_{r l}+S_{r r}}{2}, \\
& S_{\text {left }}=\frac{S_{f l}+S_{r l}}{2} ; \quad S_{\text {right }}=\frac{S_{f r}+S_{r r}}{2}, \\
& S_{\mathrm{ave}}=\frac{1}{4} \sum_{i} S_{i} \quad(i=f l, f r, r l, r r), \\
& S_{h l r}=\max \left(S_{\text {left }}, S_{\text {right }}\right) ; \quad S_{h f r}=\max \left(S_{\text {left }}, S_{\text {right }}\right) \text {, }
\end{aligned}
$$

where $S_{\text {front }}, S_{\text {rear }}, S_{\text {left }}$, and $S_{\text {right }}$ are the average slip rates of the two front wheels, the two rear wheels, the two left wheels, and the two right wheels, respectively, $S_{\text {ave }}$ is the average slip rate of all driving wheels, and $S_{h f r}, S_{h l r}$ are the maximum values of the front and rear average slip rates and the left and right average slip rates, respectively.

Based on the slip rates and the mean variables given above, the recognition algorithms of the typical road surfaces were proposed as follows.

(1) Recognition Algorithm for High Adhesion Road. As long as the four driving wheel slip rates are all in the stable slip zone, the surface is judged to be high adhesion road:

$$
S_{i} \leq \lambda_{\text {opt }} \quad(i=f l, f r, r l, r r),
$$

where $\lambda_{\text {opt }}$ is usually among $10 \%-20 \%$. Considering the tire model used in this paper, take $\lambda_{\text {opt }}=10 \%$.

(2) Recognition Algorithm for Low Adhesion Uniform Road. The condition of low adhesion and condition of uniform should be satisfied to identify this road. Driving on this road 
TABLE 4: Recognition algorithms of typical surfaces based on slip rates.

\begin{tabular}{lr}
\hline Typical surfaces & Recognition algorithms \\
\hline High & $S_{i} \leq \lambda_{\text {opt }},(i=\mathrm{fl}, \mathrm{fr}, \mathrm{rl}, \mathrm{rr})$ \\
Low and uniform & $S_{i} \geq \lambda_{\text {opt }}$ and $\sqrt{\frac{1}{4} \sum_{i}\left(S_{i}-S_{\text {ave }}\right)^{2}} \leq \varepsilon_{\text {ave }},(i=\mathrm{fl}, \mathrm{fr}, \mathrm{rl}, \mathrm{rr})$ \\
Bisectional & $S_{\text {left }} \geq \lambda_{\text {opt }}|| S_{\text {right }} \geq \lambda_{\text {opt }},\left|S_{\text {front }}-S_{\text {rear }}\right| \leq \varepsilon_{\text {fr }}$ and $\left|S_{\text {left }}-S_{\text {right }}\right| \geq \varepsilon_{\text {lr }}$ \\
Joint & $S_{\text {front }} \geq \lambda_{\text {opt }}|| S_{\text {rear }} \geq \lambda_{\text {opt }},\left|S_{\text {front }}-S_{\text {rear }}\right| \geq \varepsilon_{\text {fr }}$ and $\left|S_{\text {left }}-S_{\text {right }}\right| \leq \varepsilon_{\text {lr }}$ \\
Back to high & $S_{i} \leq \lambda_{\text {opt }}(i=\mathrm{fl}$, fr, rl, rr $)$ and $S_{\text {ave }} \leq \lambda_{p}$ \\
\hline
\end{tabular}

surface, the slip rates of all wheels are close and in unstable zone. The recognition algorithm can be expressed as

$$
\begin{gathered}
S_{i} \geq \lambda_{\text {opt }} \quad(i=f l, f r, r l, r r) \text { condition of low adhesion, } \\
\sqrt{\frac{1}{4} \sum_{i}\left(S_{i}-S_{\text {ave }}\right)^{2}} \leq \varepsilon_{\text {ave }} \quad(i=f l, f r, r l, r r)
\end{gathered}
$$$$
\text { condition of homogenous, }
$$

where $\varepsilon_{\text {ave }}$ is the limit of the homogenous condition, the uniform condition will be stricter when a smaller $\varepsilon_{\text {ave }}$ is chosen. As the acceleration of the vehicle and the ramp resistance transfer the axles load, there is inevitable difference between the front and rear slip rates. So $\varepsilon_{\text {ave }}$ should not be too small; otherwise, the condition of homogenous will be failure.

(3) Recognition Algorithm for Bisectional Road. The adhesive abilities of front and rear end are similar on this road surface, and the adhesive abilities of left and right side are obviously different. The recognition algorithm is as follows

$S_{\text {left }} \geq \lambda_{\text {opt }} \| S_{\text {right }} \geq \lambda_{\text {opt }}$ left or right side in low friction,

$\left|S_{\text {front }}-S_{\text {rear }}\right| \leq \varepsilon_{f r}$ front and rear end in small deviation,

$\left|S_{\text {left }}-S_{\text {right }}\right| \geq \varepsilon_{l r}$ left and right side in big difference,

where $\varepsilon_{f r}, \varepsilon_{l r}$ are the slip rate limits for difference judgment of front and rear end and left and right side, respectively. The selection of $\varepsilon_{f r}$ should also take account of the inevitable difference between the front and rear slip rates caused by the axle load transferring.

(4) Recognition Algorithm for Joint Road. The adhesive abilities of front and rear end are obviously different on this road surface, and the adhesive abilities of left and right side are similar. The recognition algorithm is as follows:

$S_{\text {front }} \geq \lambda_{\text {opt }} \| S_{\text {rear }} \geq \lambda_{\text {opt }}$ front or rear end in low friction,

$\left|S_{\text {front }}-S_{\text {rear }}\right| \geq \varepsilon_{f r}$ front and rear end in big difference,

$\left|S_{\text {left }}-S_{\text {right }}\right| \leq \varepsilon_{l r}$ Left and right side in small deviation.
(5) Recognition Algorithm for Roads Back to High Adhesion. Once the above recognition algorithms are satisfied, the pedal adjustment controller and the torque distribution controller will be activated into different mode. The switching conditions for the program to quit the present mode and back to the initial driving control mode as on the high adhesion road should be proposed. Obviously, the high adhesion road recognition algorithm adopted in (14) is no longer applicable; otherwise, when the vehicle drives on a constant bad surface, the driving control mode will switch frequently, causing the slip rates to change rapidly between the stable and unstable zones. Therefore, a "Road back to high adhesion recognition algorithm" was proposed as follows:

$$
\begin{gathered}
S_{i} \leq \lambda_{\text {opt }} \quad(i=f l, f r, r l, r r), \\
S_{\text {ave }} \leq \lambda_{p},
\end{gathered}
$$

where $\lambda_{p}$ is the upper limit of slip rates when judging the surface back to high adhesion; according to the tire parameters used in this paper, $\lambda_{p}$ is taken as $5 \%$.

In summary, the recognition algorithms of typical road surfaces based on slip rates were proposed as shown in Table 4.

3.3. Pedal Adjustment Control Algorithm. The pedal adjustment control system was designed to control the slip rates of the seriously slipping wheels within the stable zone and close to $\lambda_{\text {opt }}$, in order to meet the driver's torque request as well as possible.

The deviation variable was designed as

$$
e_{1}=\lambda_{h}-\lambda_{\mathrm{opt}},
$$

where $\lambda_{h}$ is the slip rate of the seriously slipping wheel. On low adhesion uniform road, $\lambda_{h}=S_{\text {ave }}$ and, on bisectional road, $\lambda_{h}=\max \left\{S_{\text {left }}, S_{\text {right }}\right\}$.

In this paper, the PI control algorithm was adopted to the pedal adjustment control system, which would lead the deviation variable, that is, $e_{1}$ approaching zero. The algorithm is as follows:

$$
F_{D}=F_{D 0}-\left(k_{p} e_{1}+k_{i} \int_{0}^{t} e_{1} d t\right)
$$

where $F_{D 0}$ is the initial value of the pedal adjustment coefficient, namely, $F_{D 0}=1, k_{p}$, and $k_{i}$ are the constants of 
proportionality of the gain link and the integral link. To make the deviation variables approaching zero, the inequalities of $k_{p}>0$ and $k_{i}>0$ should be satisfied. In addition, $F_{D}$ should be restricted within $[0,1]$. The pedal adjustment control system based on PI algorithm is shown in Figure 4.

3.4. Interaxle Torque Distribution Control Algorithm. When the vehicle is driving on the joint road or the axle load is heavily transferred, the interaxle torque distribution control system was designed to optimize the torque distribution between the axles, which would keep the slip rate difference between front and rear axle in the allowable range. According to the definition of slip rate, the algorithm could just minimize the speed difference of the axles.

The deviation variable was designed as

$$
e_{2}=\omega_{f}-\omega_{r}
$$

where $\omega_{f}, \omega_{r}$ are the speed of the front and rear axles, respectively. On the joint road, the vehicle can be simplified as a bicycle mode, as there is no difference between the speeds of the left and right wheels.

The sliding control mode has been applied to many vehicle control systems, such as the ABS control system [19] and the slip rate control system [20]. In this paper, the sliding control model was used in the interaxle torque distribution control system. Using integral switching function, the first order sliding mode plane and the reaching law were designed as

$$
\begin{gathered}
s=e_{2}+c \int_{0}^{t} e_{2} d t, \\
\dot{s}=-k_{s} \operatorname{sgn}(s),
\end{gathered}
$$

where $k_{s}$ denotes the approach speed and $c$ is the integral coefficient satisfying $c>0$.

According to the motion equation on driving condition, considering a bicycle model, the equations were deduced as

$$
\begin{gathered}
I_{f} \dot{\omega}_{f}=T_{m f} \eta i_{g} i_{0}-\left(I_{0}+I_{g} i_{0}^{2}\right) \dot{\omega}_{f}-F_{x f} R-F_{z f} f_{r} R, \\
I_{r} \dot{\omega}_{r}=T_{m r} \eta i_{g} i_{0}-\left(I_{0}+I_{g} i_{0}^{2}\right) \dot{\omega}_{r}-F_{x r} R-F_{z r} f_{r} R,
\end{gathered}
$$

where $I_{f}=I_{r}=2 I_{W}$ are the moment of inertia of the front and rear wheels, respectively, $F_{x f}=F_{x f l}+F_{x f r}, F_{z f}=$ $F_{z f l}+F_{z f r}$ are the longitudinal and vertical force of the front wheels, respectively, and $F_{x r}=F_{x r l}+F_{x r r}, F_{z r}=F_{z r l}+F_{z r r}$ are the longitudinal and vertical force of the front wheels, respectively.

Substituting (24) into (23)

$$
\begin{aligned}
\dot{s}= & \dot{\omega}_{f}-\dot{\omega}_{r}+c e_{2} \\
= & \frac{\left(T_{m f}-T_{m r}\right) \eta i_{g} i_{0}-\left(F_{x f}-F_{x r}\right) R-\left(F_{z f}-F_{z r}\right) f_{r} R}{2 I_{W}+I_{0}+I_{g} i_{0}^{2}} \\
& +c e_{2} .
\end{aligned}
$$

According to the driver's driving intention

$$
\begin{gathered}
T_{\text {desire }}=A_{\mathrm{ps}} F_{D}\left(T_{f \max }+T_{r \max }\right)=T_{m f}+T_{m r}, \\
F_{T, \text { desire }}=\frac{T_{m f}}{T_{\text {desire }}} .
\end{gathered}
$$

Substituting (26) into (25) and replacing $\dot{s}$ with $\dot{s}=$ $-k_{s} \operatorname{sgn}(s)$,

$$
\begin{aligned}
F_{T, \text { desire }}= & \frac{1}{2}+\left(\left(F_{x f}-F_{x r}\right) R+\left(F_{z f}-F_{z r}\right) f_{r} R\right. \\
& \left.-\left(2 I_{W}+I_{0}+I_{g} i_{0}^{2}\right)\left(-k_{s} \operatorname{sgn}(s)+c e_{2}\right)\right) \\
& \times\left(2 \eta i_{g} i_{0} A_{\mathrm{ps}} F_{D}\left(T_{f \max }+T_{r \max }\right)\right)^{-1} .
\end{aligned}
$$

Considering the validity conditions of sliding control algorithm as follows:

$$
\begin{gathered}
\dot{V}=s \dot{s}=s\left[-k_{s} \operatorname{sgn}(s)\right]=-k_{s}|s| \leq-\varepsilon_{s}|s|, \\
k_{s} \geq \varepsilon_{s}>0, \quad c>0,
\end{gathered}
$$

where $V=s^{2} / 2$ and $\varepsilon_{s}$ is a positive constant to guarantee the condition of $k_{s}>0$, the larger $\varepsilon_{s}$ is, the faster the results will approach the sliding surface but the severer the vibration of the system will be as the approach speed $\left(k_{s}\right)$ gets greater.

3.5. Control Flow of the Driving Control System. In accordance with the designed driving control strategies and the proposed recognition algorithms of typical surfaces, using the established pedal adjustment control system and the torque distribution control system above, the driving control flow for the longitudinal dynamics of the vehicle with independently driven front and rear wheels was designed as shown in Figure 5.

The driving control flow shown in Figure 5 proceeds as follows: Firstly, the program analyses the driver's torque demand according to the signal of the acceleration pedal, then the present surface is recognized based on the algorithms shown in Table 4, next, the driving control strategies is selected and activated according to Table 3 until the surface recovery to be in high adhesion condition, and the driving control strategies get back to the initial mode. Then, the program continues to judge the surface type and select the corresponding strategies constantly to guarantee the adaptability of the vehicle on various typical surfaces. 


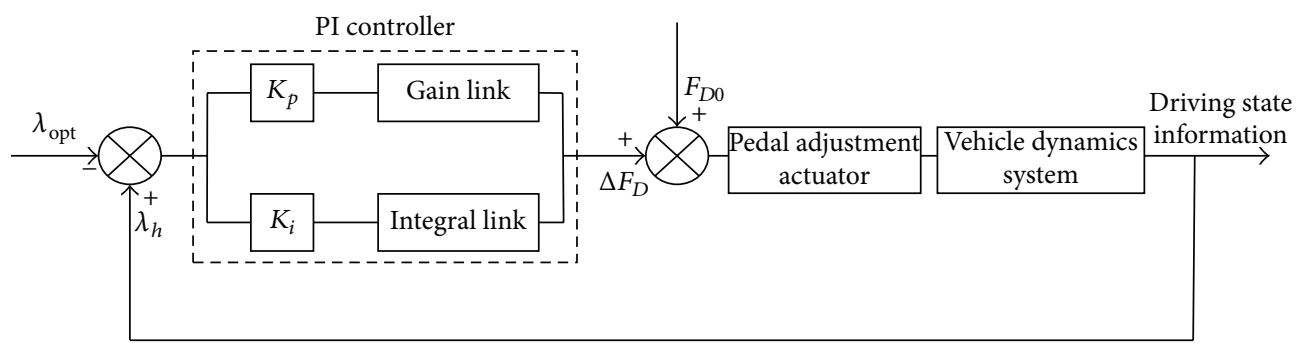

FIgURE 4: Pedal adjustment control system based on PI algorithm.

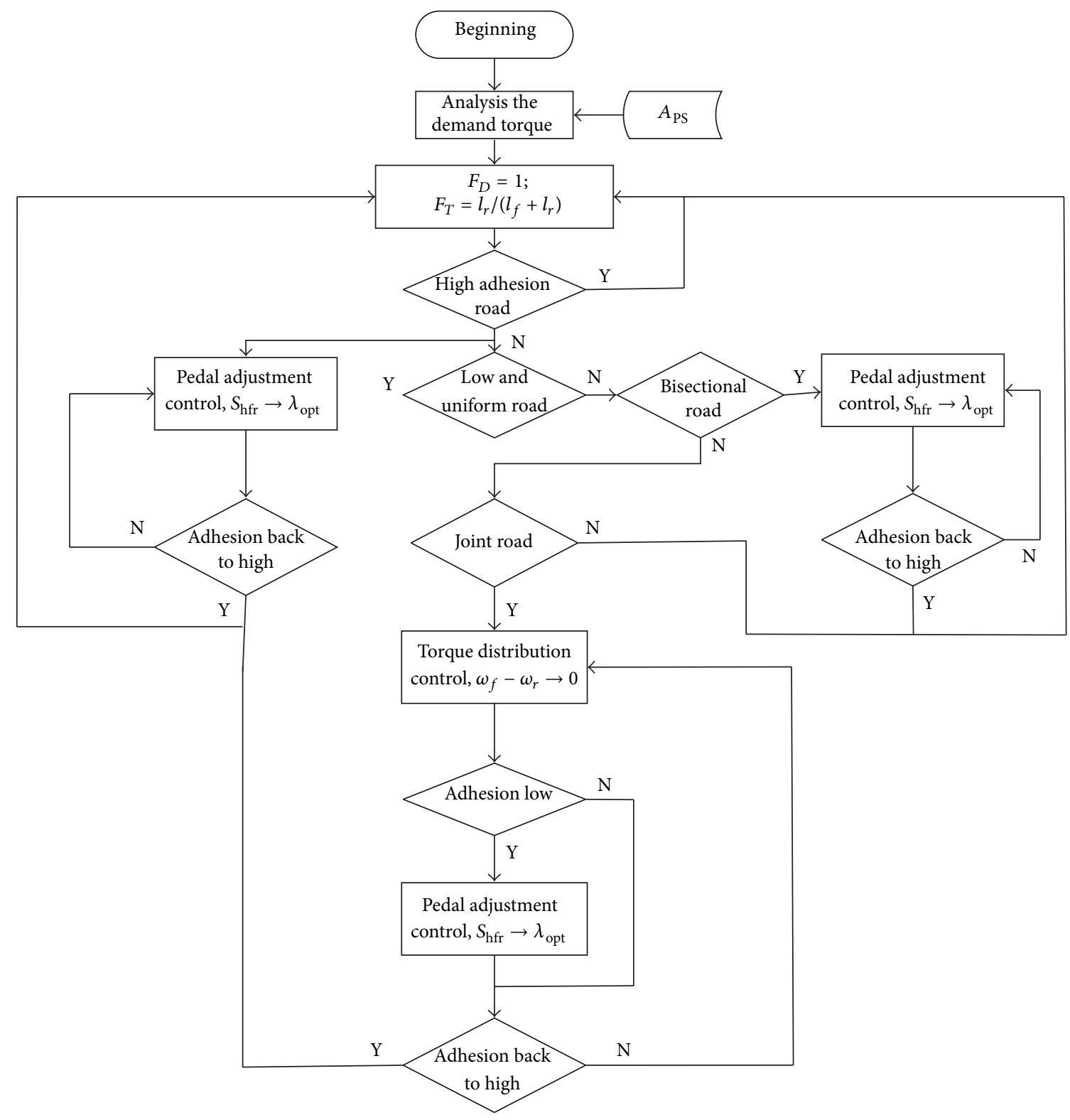

FIGURE 5: Control flow of the driving control system. 


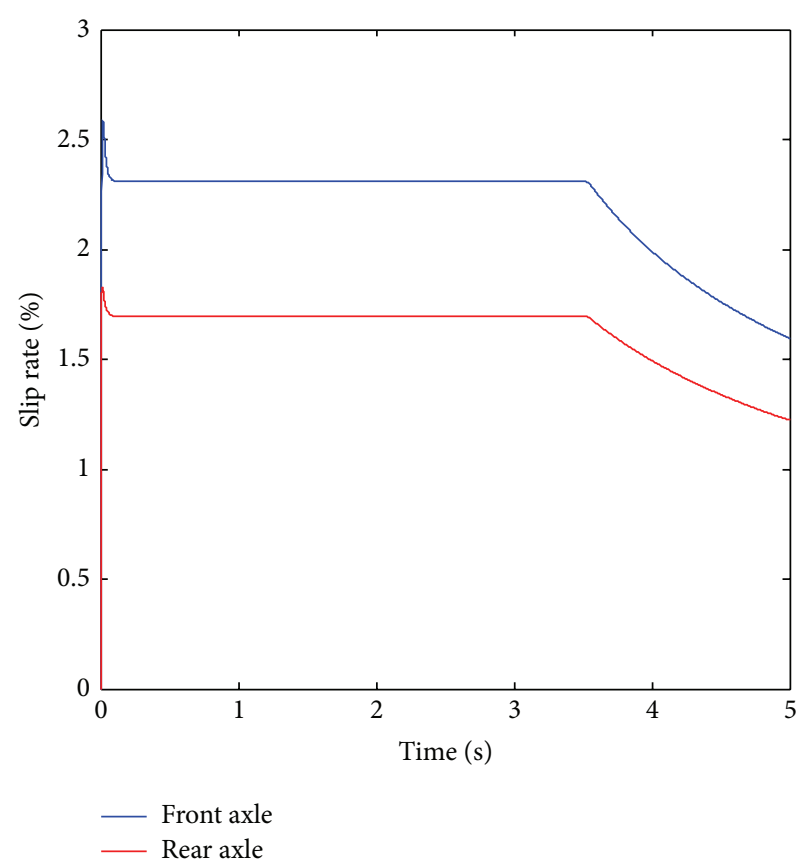

(a)

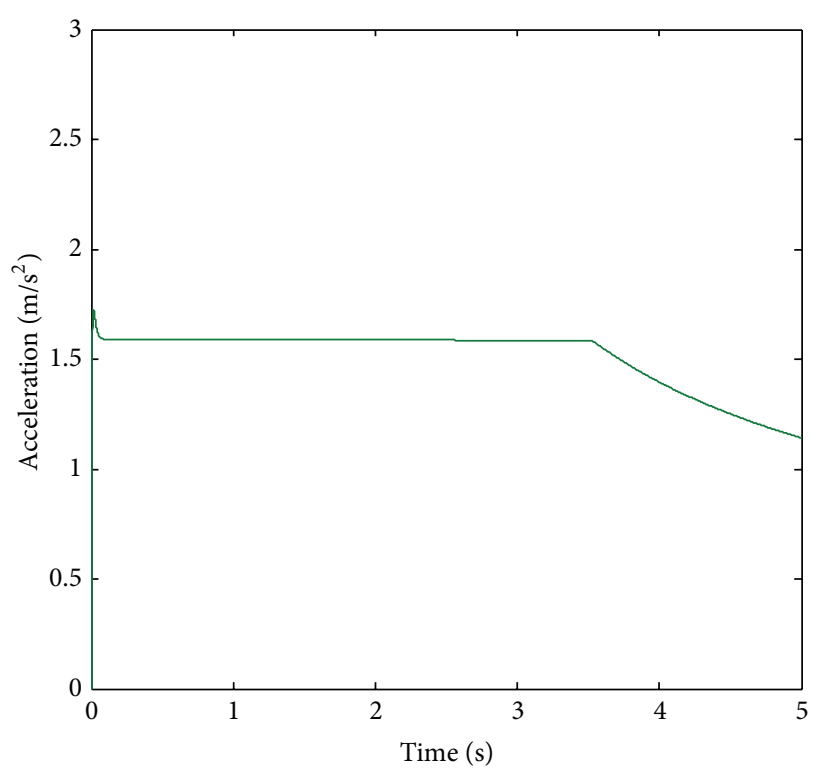

(b)

FIGURE 6: Simulation results with average torque distribution on high adhesion road: (a) slip rates of the front and rear axles; (b) acceleration of the vehicle.

\section{Simulation Results and Analysis}

4.1. The Typical Road Simulation Parameters. The road adhesion conditions are represented by the peak adhesion coefficients at each wheel. Use to represent the peak adhesion coefficients at front and left wheel, front and right wheel, rear and left wheel and rear and right wheel, respectively. This paper set the surface parameters at each wheel of different typical surfaces as shown in Table 5 .

In Table 5, the adhesion coefficients of high adhesion road, low adhesion and uniform surface, bisectional road are constant, and the coefficients of joint road represent the adhesive difference between the front and rear wheels when the vehicle is driving through an adhesion step change surface, and the actuation duration of the step adhesion parameter is associated with the wheelbase and the velocity of the vehicle.

\subsection{The Simulation Analysis for the Typical Roads}

4.2.1. Straight Acceleration on High Adhesion Road. Figures 6 and 7 show the simulation results of two driving control strategies on high adhesion road, which are the torque average distribution model $\left(F_{T}=0.5\right)$ and the fixed proportion distribution according to the static axles load mode $\left(F_{T}=\right.$ $\left.l_{r} /\left(l_{f}+l_{r}\right)\right)$, on the condition of the acceleration pedal signal being set as 0.5 .

The simulation results show that the fixed proportion torque distribution mode according to the static axles load
TABle 5: Adhesion coefficients of typical surfaces.

\begin{tabular}{lc}
\hline Typical surfaces & Adhesion coefficients $\left(f_{\text {sfl }}, f_{\text {sfr }}, f_{\text {srl }}, f_{\text {srr }}\right)$ \\
\hline High adhesion & $(0.8,0.8,0.8,0.8)$ \\
Low and uniform & $(0.2,0.2,0.2,0.2)$ \\
Bisectional & $(0.2,0.8,0.2,0.8)$ \\
Joint & $(0.2,0.2,0.8,0.8)$ \\
\hline
\end{tabular}

can significantly reduce the slip rate difference of front and rear wheels with no reduction of the vehicle acceleration, which is beneficial to the equal life design of the tires as the wear rates of the front and rear wheels are similar. As the acceleration of the vehicle and the ramp resistance transfer the axles load, and the longitudinal force and the vertical force of the tire have nonlinear relationship, there is inevitable difference between the front and rear slip rates, which, however, would not influence the dynamics performance of the vehicle on high adhesion road.

\subsubsection{Straight Acceleration on Low Adhesion Uniform Road.} Figures 8 and 9 show the simulation results on low adhesion uniform road with and without the pedal adjustment PI control, respectively. The acceleration pedal signal was set as 0.5 and the "fixed proportion distribution model" was adopted.

The simulation results show that, without pedal adjustment control, the slip rates of the front and rear wheels were in unstable zone when the motor works in the high torque zone, 


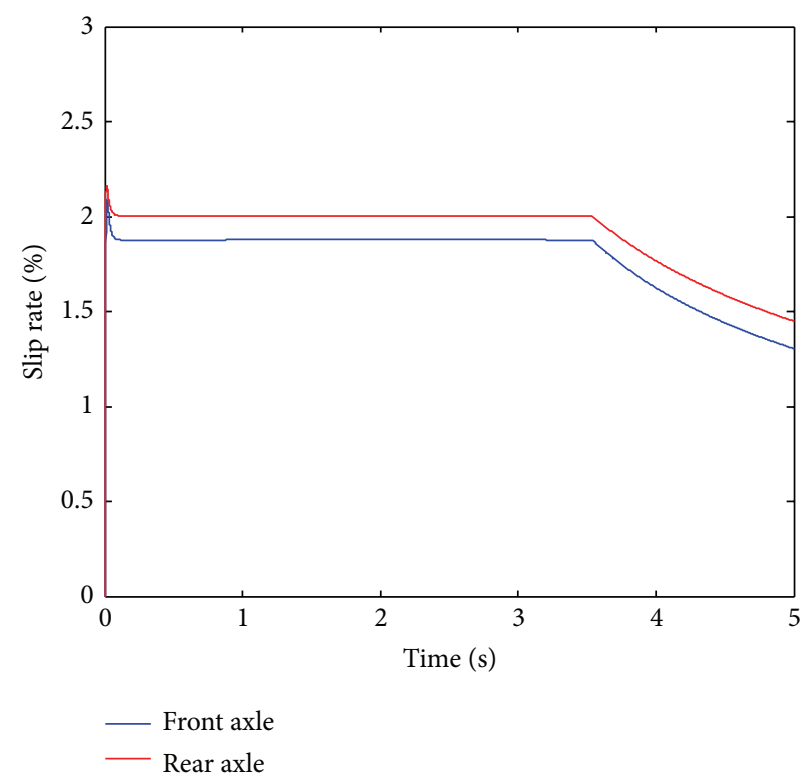

(a)

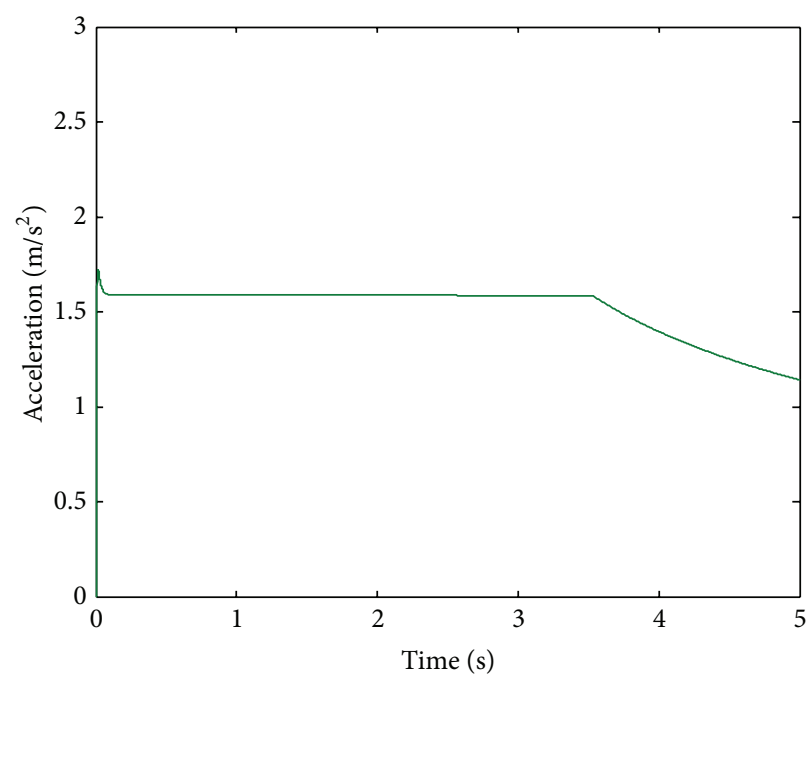

(b)

FiguRE 7: Simulation results with fixed proportion torque distribution on high adhesion road: (a) slip rates of the front and rear axles; (b) acceleration of the vehicle.

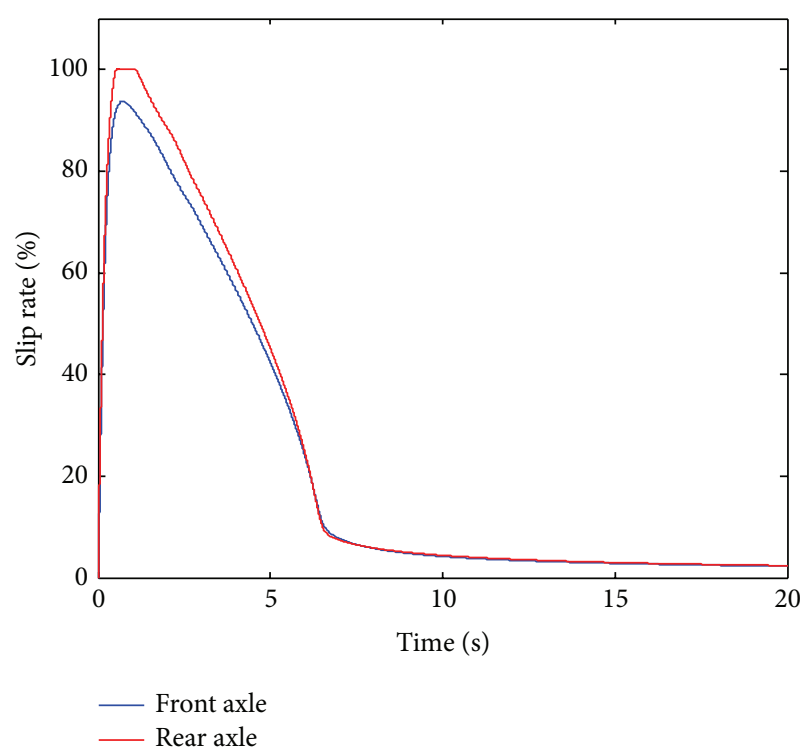

(a)

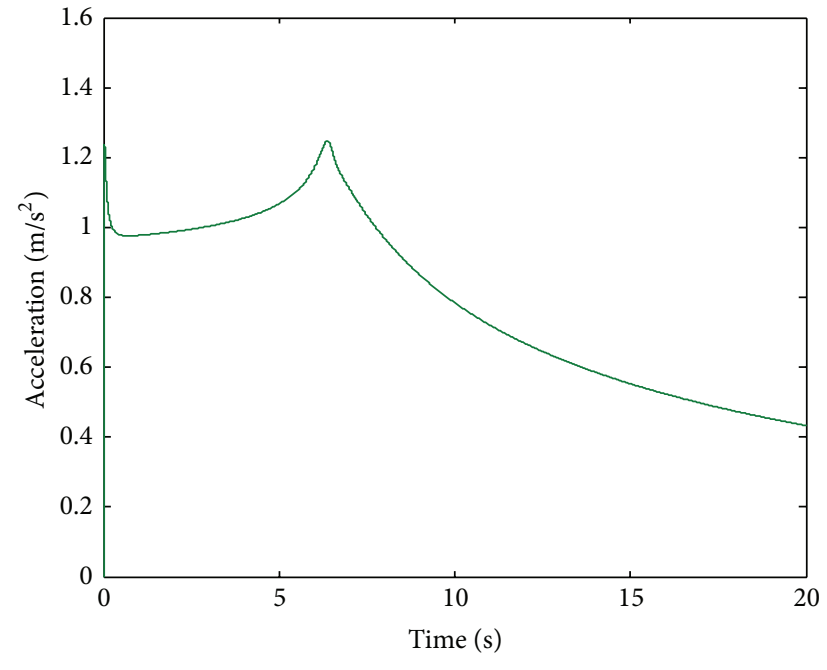

(b)

FIGURE 8: Simulation results without pedal control on low adhesion and homogenous surface: (a) slip rates of the front and rear axles; (b) acceleration of the vehicle. 


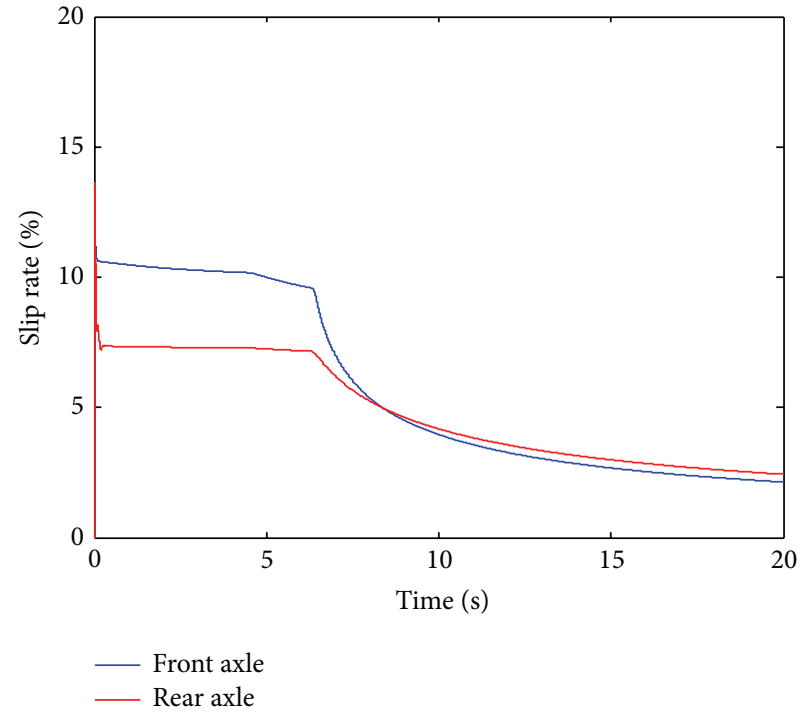

(a)

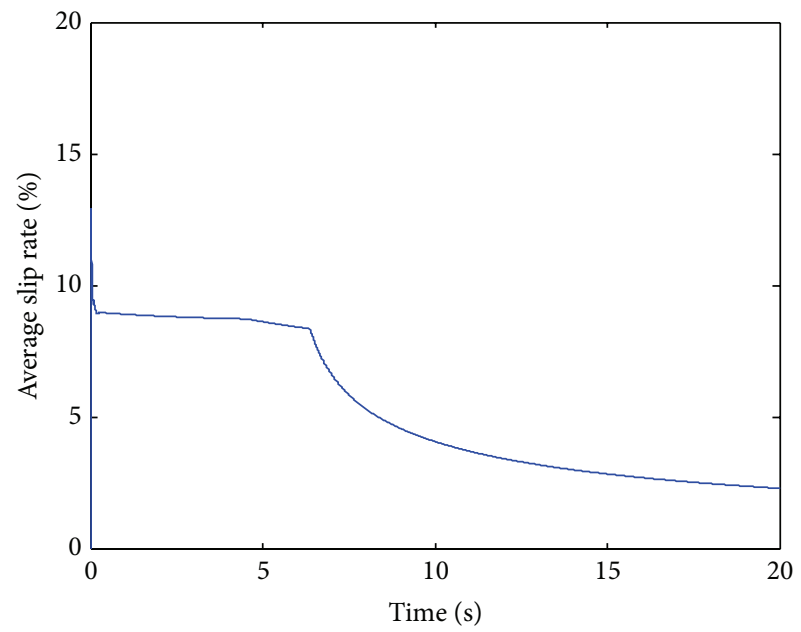

(c)

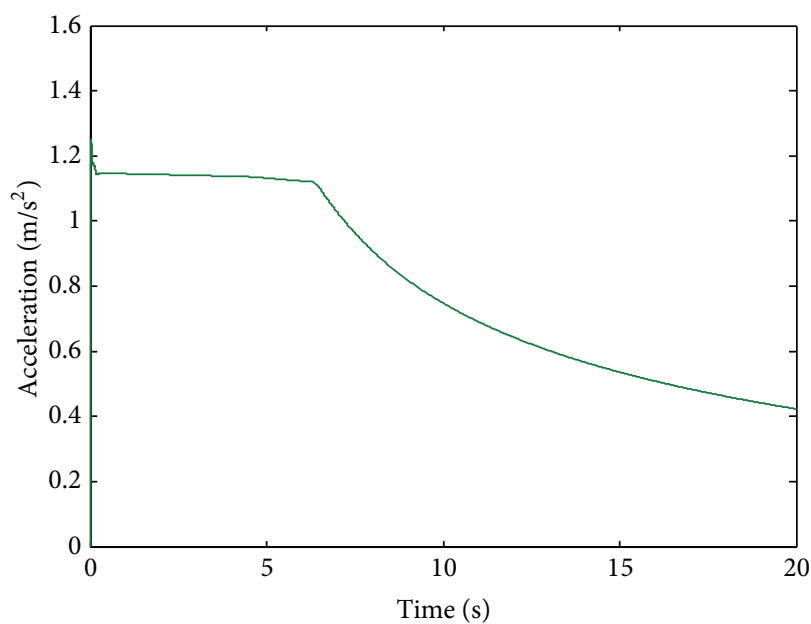

(b)

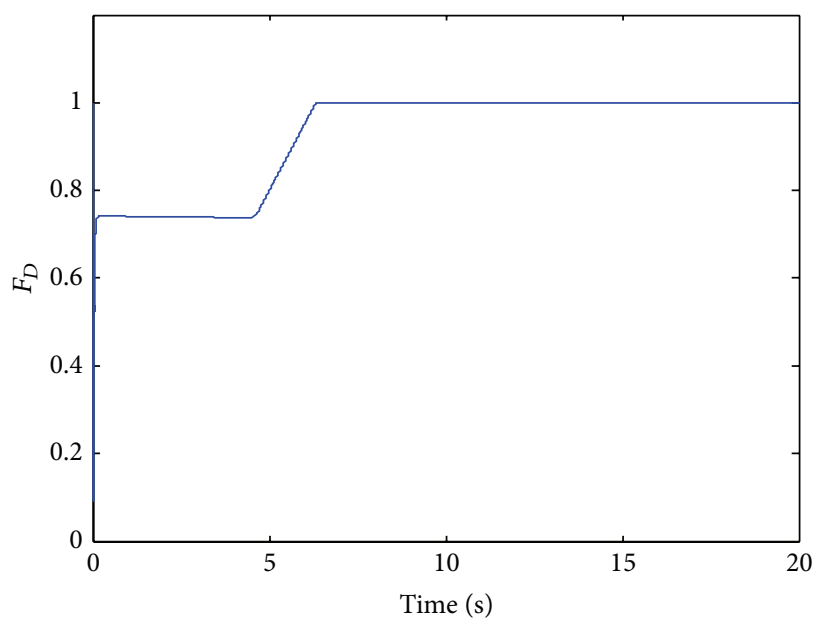

(d)

FIGURE 9: Simulation results with pedal adjustment control on low adhesion and homogenous surface: (a) slip rates of the front and rear wheels on the left side; (b) acceleration of the vehicle; (c) average slip rate of the wheels; (d) the pedal adjustment coefficient.

as shown in Figure 8(a), which might cause sideslip, drift, and other dangers as the lateral adhesion would be low in such situation. When the pedal adjustment control was adopted, the slip rates were kept in stable zone at the whole range of the motor speed zone, and when the motor torque was high, the slip rates were controlled close to $\lambda_{\text {opt }}$ as shown in Figure 9(a). Comparing Figure 8(b) with Figure 9(b), when the motor worked at high torque zone, the vehicle had larger acceleration; namely, the power performance was improved when the pedal adjustment control was adopted. Figures 9(c) and $9(\mathrm{~d})$ show the average slip rate of the four wheels and the pedal adjustment coefficient, respectively. When the motor worked in the high torque zone, $F_{D}$ was controlled close to 0.75 . Then along with the motor speed rising, the maximum torque motor could provide declines, which reduced the desired driving torque as shown in (2). When the desired driving torque was reduced to the reverse torque, the road surface could provide, the pedal adjustment coefficient began to rise till $F_{D}=1$ and kept constant afterward.

4.2.3. Straight Acceleration on Bisectional Road. Figures 10 and 11 show the simulation results on bisectional road (low adhesion on left side and high on the right) with and without the pedal adjustment PI control, respectively. The acceleration pedal signal was set as 0.5 and the "fixed proportion distribution model" was adopted.

The simulation results show that, without pedal adjustment control, the slip rates of the wheels at the low adhesion 


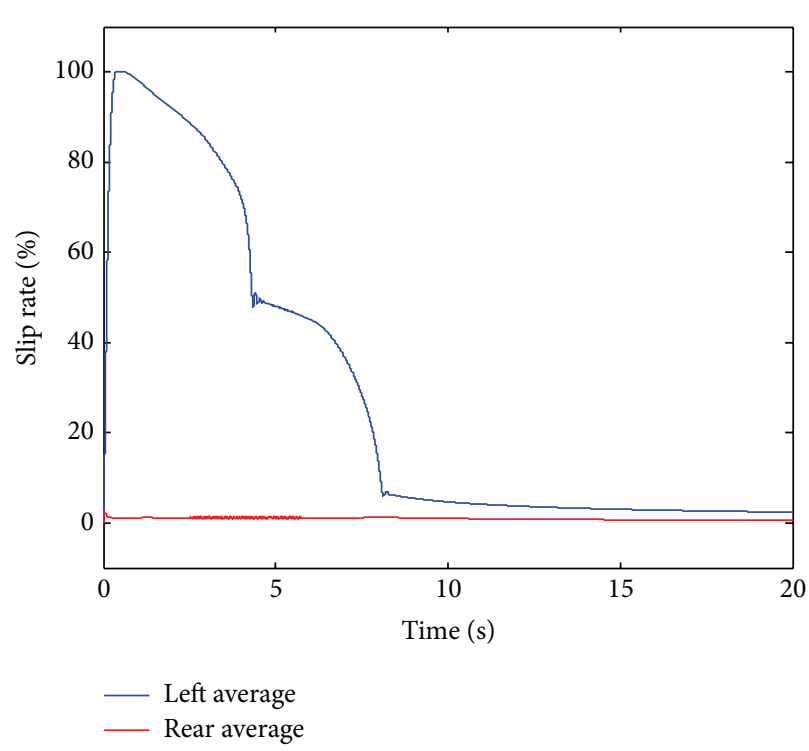

(a)

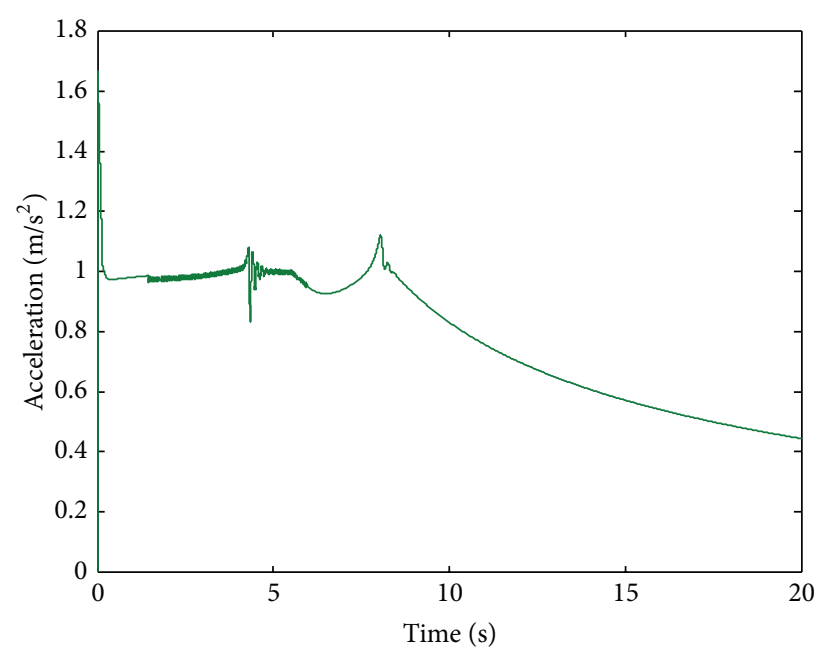

(b)

FIGURE 10: Simulation results without pedal control on bisectional road: (a) average slip rates of the left and right side wheels; (b) acceleration of the vehicle.

side were in unstable zone and the slip rates of the wheels at the high adhesion side were in stable zone when the motor worked in the high torque zone, as shown in Figure 10(a). When the pedal adjustment control was adopted, the slip rates were regulated back to stable zone rapidly. And when the motor worked in the high torque zone, the slip rates of the low adhesion side are controlled close to $\lambda_{\text {opt }}$ as shown in Figure 11(a). Comparing Figure 10(b) with Figure 11(b), when the motor worked at high torque zone, as the adhesive ability of the low adhesion side was fully used, the vehicle had larger acceleration, which means the power performance was improved when the pedal adjustment control was adopted. Figure 11(c) shows the slip rates of the front and rear wheels on the low adhesion side, which were controlled close to $\lambda_{\text {opt }}$ with an inevitable deviation. Figure 11(d) shows the pedal adjustment coefficient during the simulation, which was similar to the simulation results shown in Figure $9(\mathrm{~d})$.

4.2.4. Straight Acceleration on Joint Road. Figures 12 and 13 show the simulation results on joint road (from high adhesion surface to low adhesion surface) with and without the torque distribution SMC control system, respectively. The acceleration pedal signal was set as 0.5 . The simulation covers three kinds of surfaces in total, namely, high adhesion surface, joint road, and low adhesion surface. The torque distribution controller was activated when the vehicle was driving through the joint surface and the recognition algorithm of joint road was satisfied.

The simulation results in Figure 12 show that, without the torque distribution control, the front wheels get into the low adhesion surface at approximately $4.2 \mathrm{~s}$. As the adhesion at front axle was low, the slip rates of the front wheels rise into the unstable zone rapidly, as shown in Figure 12(a), which increased the slip rate difference between the front and rear instantly, as shown in Figure 12(b). At the same time, the output torques of the motors reduced as the calculated torque demand decreased for the maximum torque the motor could provide at present speed being low, as shown in Figure 12(c); as a result, the acceleration of the vehicle reduced instantly as shown in Figure 12(d). Subsequently, after about $4.6 \mathrm{~s}$, the rear wheels get into the low adhesion surface, and the slip rates of the rear wheels and the speed of the rear motor became high, which lead to a further reduction of the calculated torque demand. In summary, when driving from high adhesion surface to low adhesion surface, the acceleration of the vehicle reduced rapidly, the power of the vehicle was not fully used, and as the slip rates rise into the unstable zone, the lateral adhesion of the vehicle was low, which might cause sideslip, drift, and other dangers.

The simulation results in Figure 13 show that once the recognition algorithm of adhesion surface was satisfied, the torque distribution SMC control system would be activated and the torque distribution coefficient reduced rapidly as shown in Figure 13(e), which would fully inhibit the rising of the front wheels' slip rates. The slip rate difference between the front and rear wheels converged quickly to reasonable zone, as shown in Figure 13(b). Figure 13(c) shows that when the vehicle was driving through the joint road, the torque output of the front motor fell down and the rear motor rose up, and the adhesion ability of the high adhesion was fully used. Comparing Figure 12(d) with Figure 13(d), as the torque distribution control made maximum use of the front and rear surface adhesion, the vehicle acceleration in the adhesion step 


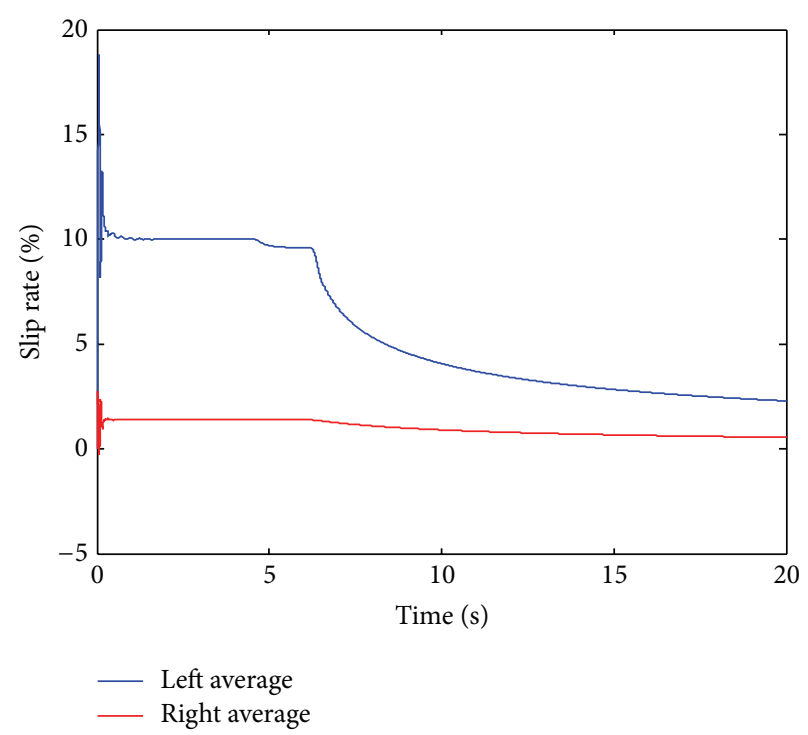

(a)

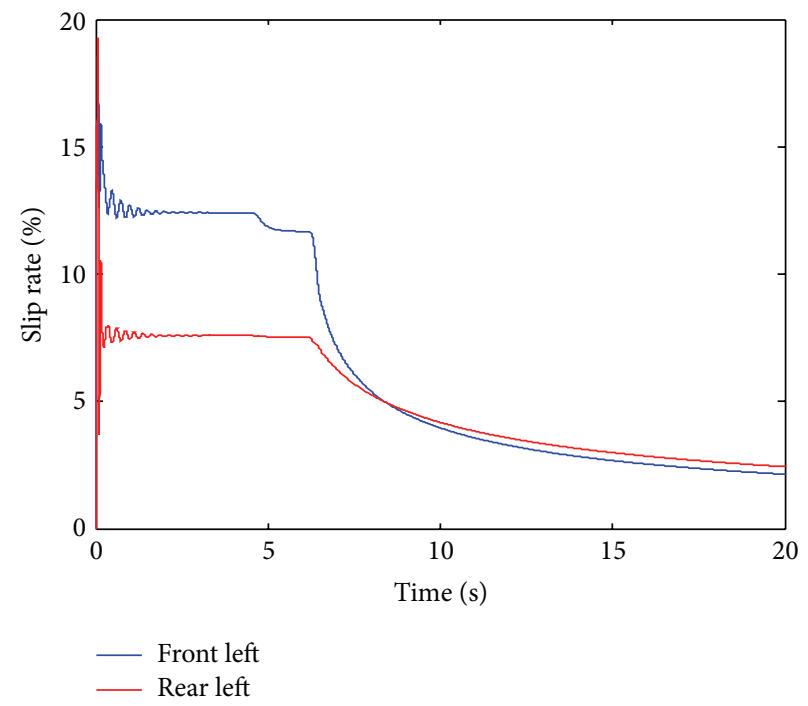

(c)

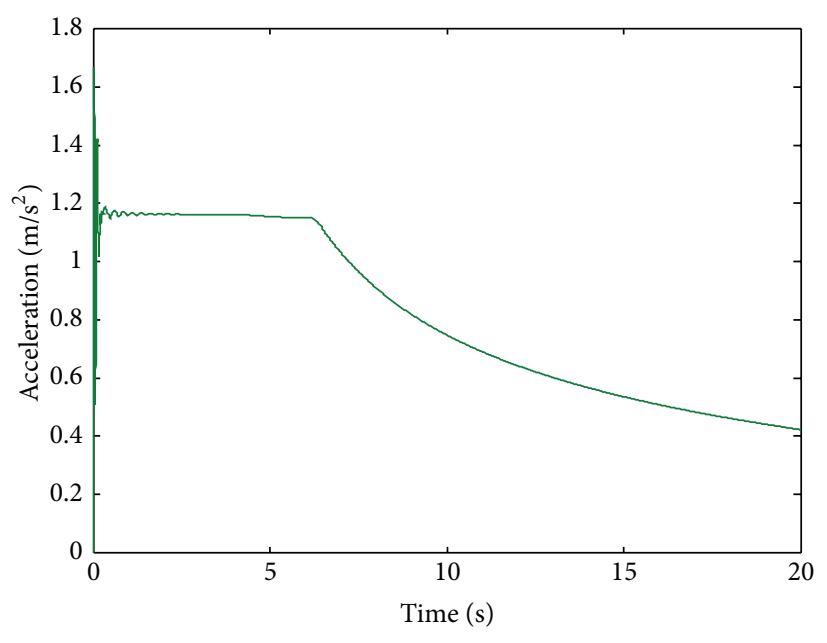

(b)

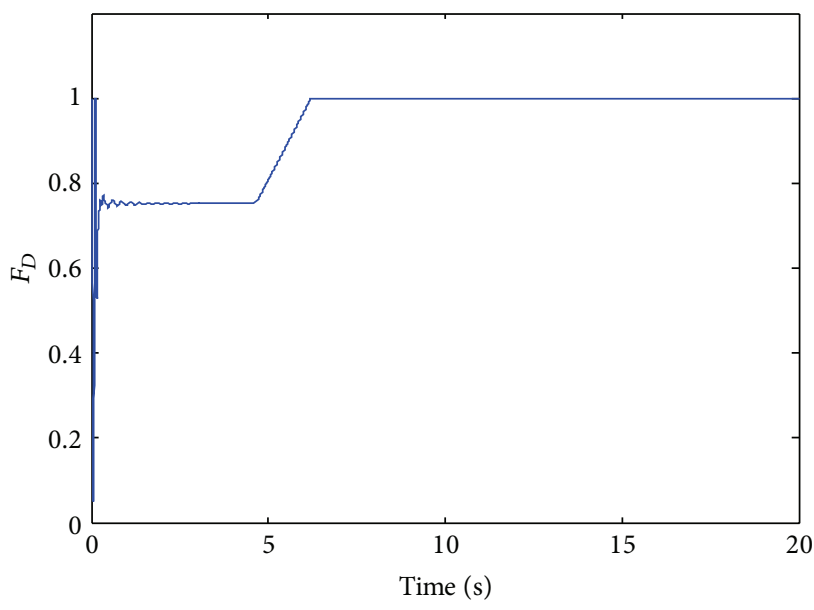

(d)

FIGURE 11: Simulation results with pedal adjustment control on bisectional road: (a) average slip rates of the left and right side wheels; (b) acceleration of the vehicle; (c) slip rates of the front and rear wheels on the left side; (d) the pedal adjustment coefficient.

area increased dramatically and the dynamic performance of the vehicle was guaranteed. During the whole accelerating process, the slip rates were in stable zone, the recognition algorithm of low adhesion surface was not satisfied, so the pedal adjustment controller was not activated, and the pedal adjustment coefficient was constant 1 . At about $7.3 \mathrm{~s}$, when the slip rate difference between the front and rear wheels reached 0 , the SMC control system reached the sliding surface and remained stable, and the torque distribution coefficient went back to the initial value according to the axle load proportion as shown in Figure 13(e), and then the control system had small, high frequency oscillation, which is the inherent characteristics of sliding control systems. In summary, when the vehicle was driving from the high adhesion surface to the low, with the torque distribution control, the dynamic performance of the vehicle was fully guaranteed and the slip rates were controlled within stable zone so that the vehicle had enough lateral adhesion.

\section{Conclusions}

(1) For a front and rear axle independently driven system, an $8 \mathrm{DOF}$ dynamics model of the vehicle system was 


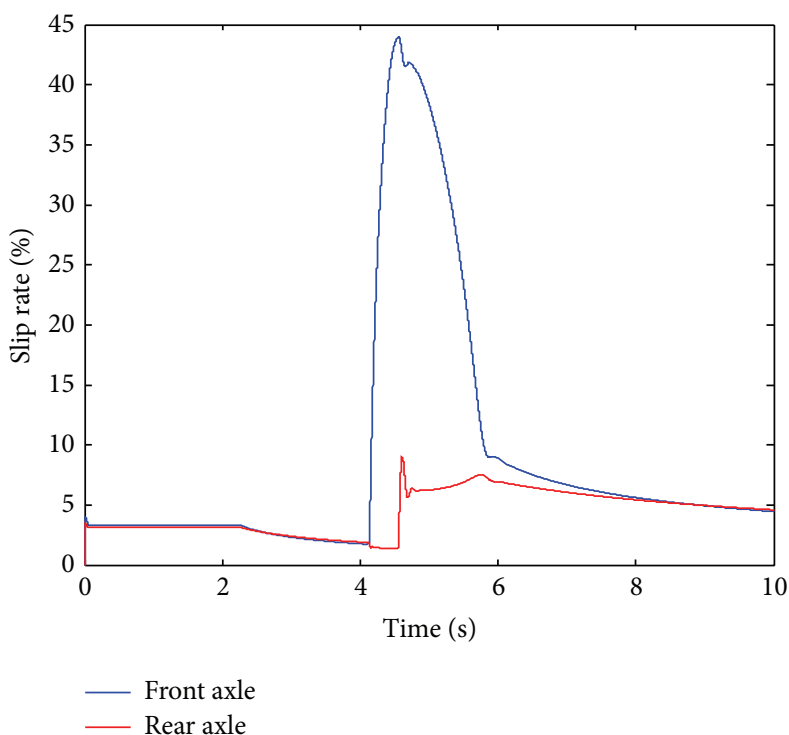

(a)

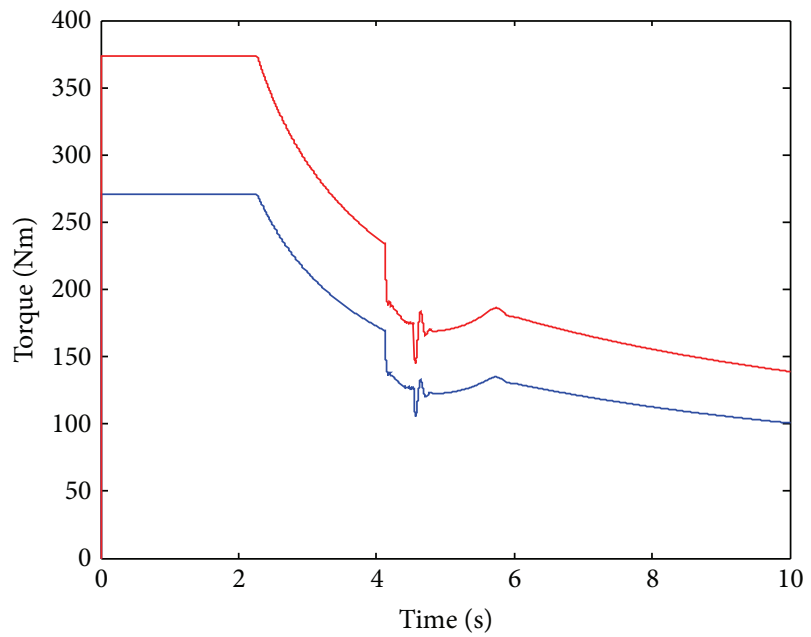

- Front motor

Rear motor

(c)

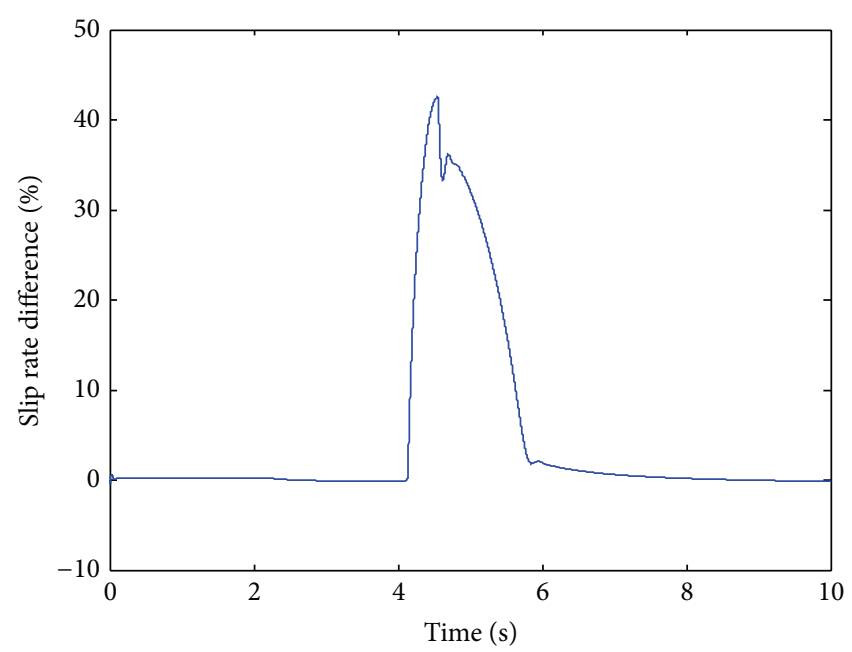

(b)

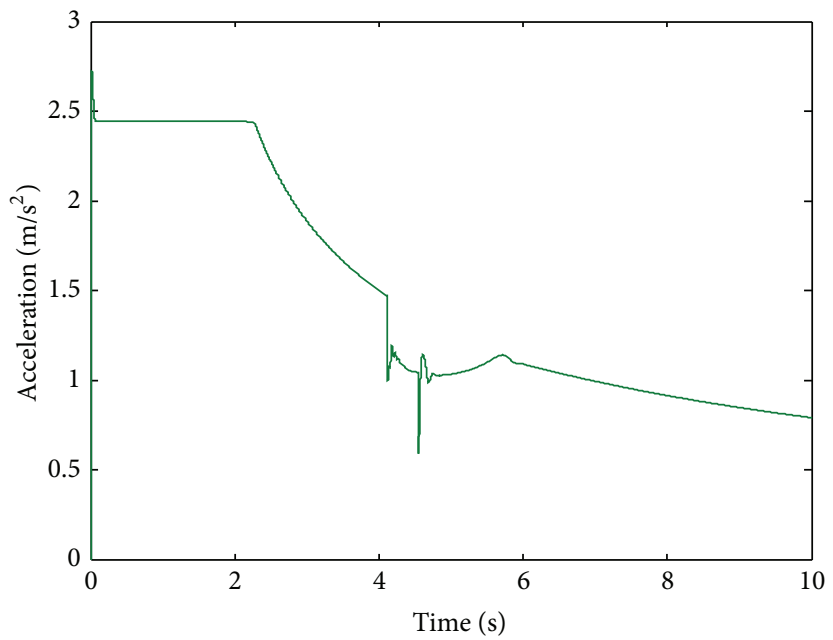

(d)

FIGURE 12: Simulation results without torque distribution control on joint road: (a) average slip rates of the front and rear wheels; (b) slip rate difference between front and rear wheels; (c) output torques of the front and rear wheels; (d) acceleration of the vehicle.

established, which serves as the testing platform of the driving control strategies.

(2) The driving control strategies for different typical surfaces were studied, and the recognition algorithms for the typical surfaces based on the slip rates were proposed. Two control systems including the pedal adjustment control system based on PI algorithm and the torque distribution control system based on SMC algorithm were designed. The driving control flow of the electric vehicle with independently driven front and rear wheels was developed.
(3) Several simulation experiments were carried out, we compared the simulation results of the slip rates, the accelerations and so forth, under different driving control strategies, which confirmed the rationality of the strategies on different typical surfaces. The pedal adjustment control system could effectively prevent the slipping of the driving wheel, and the interaxle torque distribution system could reduce the slip difference between the front and rear wheels. As a result, the dynamic performance and safety of the vehicle were ensured. 


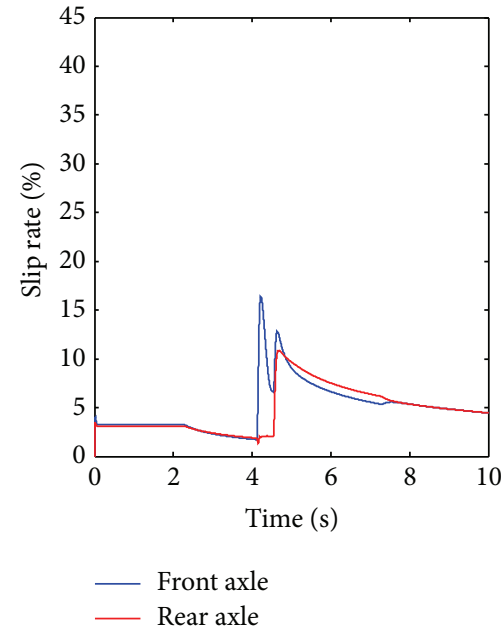

(a)

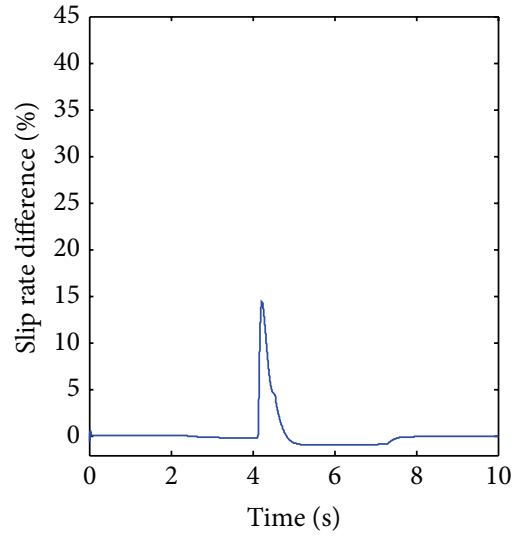

(b)

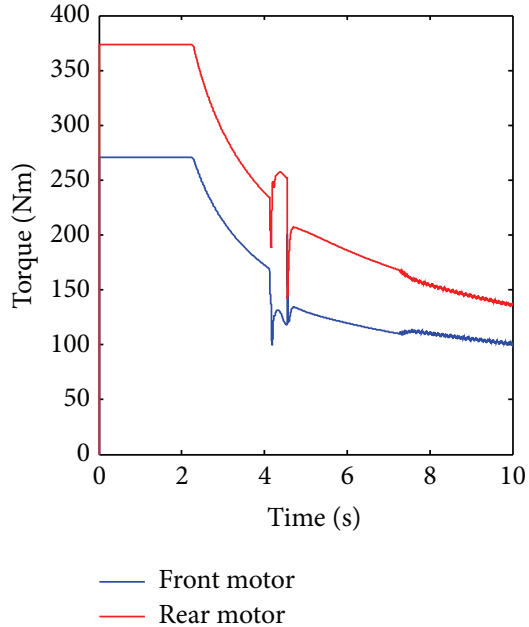

(c)

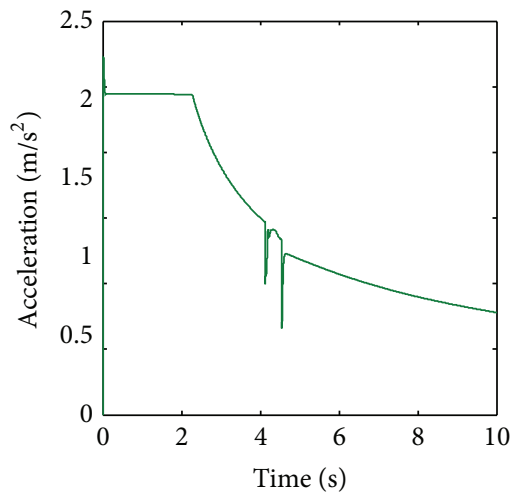

(d)

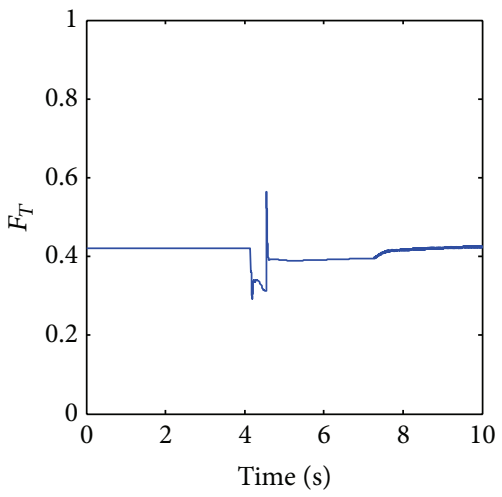

(e)

FIGURE 13: Simulation results with torque distribution control on joint road: (a) average slip rates of the front and rear wheels; (b) slip rate difference between front and rear wheels; (c) output torques of the front and rear wheels; (d) acceleration of the vehicle; (e) the torque distribution coefficient.

\section{Conflict of Interests}

The authors declare that there is no conflict of interests regarding the publication of this paper.

\section{References}

[1] J. Peng, H. He, and N. Feng, "Simulation research on an electric vehicle chassis system based on a collaborative control system," Energies, vol. 6, no. 1, pp. 312-328, 2013.

[2] Y. Wang, Study on traction control system for four wheel drive vehicle based on inter-axle torque distribution [thesis], Chongqing University, 2009.

[3] J. Fan, Y. Luo, and K. Li, "Development of supervisory control system for multi-axle independent drive hybrid vehicle," Journal of Mechanical Engineering, vol. 46, no. 10, pp. 126-131, 2010.

[4] Z. Zhao, N. He, Y. Zhu, and Z. Yu, "Mode transition control for four wheel drive hybrid electric car," Journal of Mechanical Engineering, vol. 47, no. 4, pp. 100-109, 2011.

[5] D. Kim, S.-H. Hwang, and H. Kim, "Advanced active safety system using separated front and rear motor control for a $4 \mathrm{WD}$ hybrid electric vehicle," Diffusion and Defect Data B, vol. 120, pp. 223-228, 2007.

[6] N. Mutoh, Y. Takahashi, and Y. Tomita, "Failsafe drive performance of FRID electric vehicles with the structure driven by the front and rear wheels independently," IEEE Transactions on Industrial Electronics, vol. 55, no. 6, pp. 2306-2315, 2008.

[7] M. Bian and S. Chen, "Study of a system for an anti-slip regulation," Journal of Wuhan Automobile Polytechnic University, vol. 22, no. 6, pp. 42-45, 2000.

[8] S.-J. Zhou, Y.-T. Luo, X.-D. Huang, and X.-F. Fu, "Slip rate identification and traction control of 4WD electric vehicle," Journal of South China University of Technology, vol. 36, no. 6, pp. 95-107, 2008.

[9] G. Wang, Z. Liu, R. Hu, and B. Wang, "Fuzzy logic direct adaptive control of abs-equipped vehicles based on equivalent slip differential of tire," Chinese Journal of Mechanical Engineering, vol. 44, no. 11, pp. 242-247, 2008.

[10] Z. Qi, Research on control technology of anti-slip regulation in integrated $A B S / A S R / A C C$ system for motor vehicles [thesis], Beijing Institute of Technology, 2004.

[11] L. Li, S. Kodama, and Y. Hori, "Design of anti-slip controller for an electric vehicle with an adhesion status analyzer based on the 
EV simulator," Asian Journal of Control, vol. 8, no. 3, pp. 261-267, 2006.

[12] N. Mutoh, T. Kazama, and K. Takita, "Driving characteristics of an electric vehicle system with independently driven front and rear wheels," IEEE Transactions on Industrial Electronics, vol. 53, no. 3, pp. 803-813, 2006.

[13] J. Kang, J. Yoo, and K. Yi, "Driving control algorithm for maneuverability, lateral stability, and rollover prevention of 4WD electric vehicles with independently driven front and rear wheels," IEEE Transactions on Vehicular Technology, vol. 60, no. 7, pp. 2987-3001, 2011.

[14] Z. Zhao, J. Gu, and Z. Yu, "Study of acceleration slip regulation strategy for four wheel drive hybrid electric car," Journal of Mechanical Engineering, vol. 47, no. 14, pp. 83-98, 2011.

[15] S. Song, J. Gong, W. Lin, and G. Wang, "Modeling and simulation of space vector control system for pure electric vehicle driven by permanent magnet synchronous motor," Journal of Wuhan University of Technology, vol. 34, no. 4, pp. 118-122, 2012.

[16] C. Wang, Y. Ji, H. Luan, and Z. Zhang, "Simulation of PMSM vector control system based on MATLAB/SIMULINK," Journal of Jilin University, vol. 27, no. 1, pp. 17-22, 2009.

[17] H. B. Pacejka and E. Bakker, "Magic formula tyre model," Vehicle System Dynamics, vol. 21, supplement, pp. 1-18, 1993.

[18] H. B. Pacejka, Tire and Vehicle Dynamics, Butterworth Heinemann Publications, Oxford, UK, 2002.

[19] Z. Huang, X. Yi, M. Sun, and E. Mao, "Using ADAMS and MATLAB for ABS sliding mode control simulation," Computer Engineering and Applications, vol. 47, no. 11, pp. 245-248, 2011.

[20] B. Subudhi and S. S. Ge, "Sliding-mode-observer-based adaptive slip ratio control for electric and hybrid vehicles," IEEE Transactions on Intelligent Transportation Systems, vol. 13, no. 4, pp. 1617-1626, 2012. 


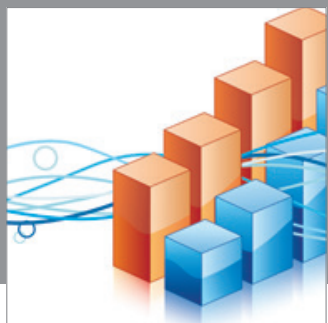

Advances in

Operations Research

mansans

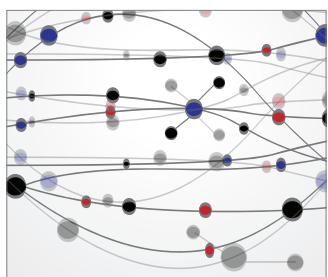

The Scientific World Journal
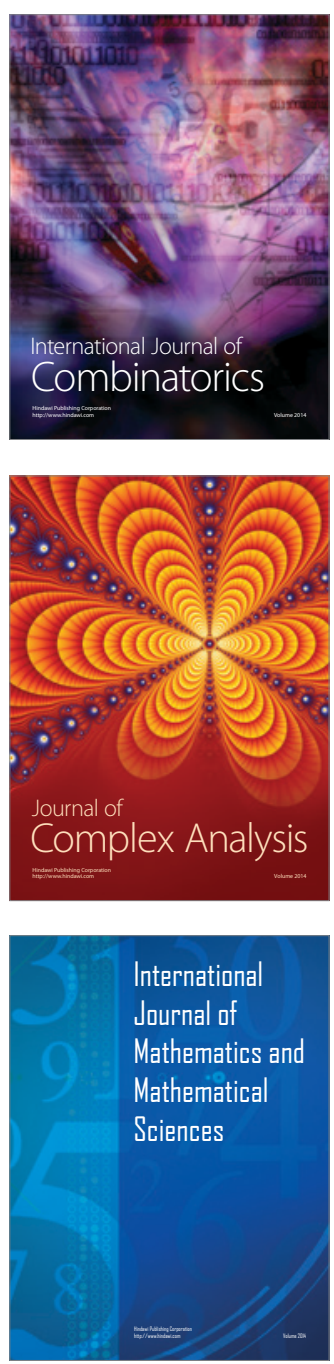
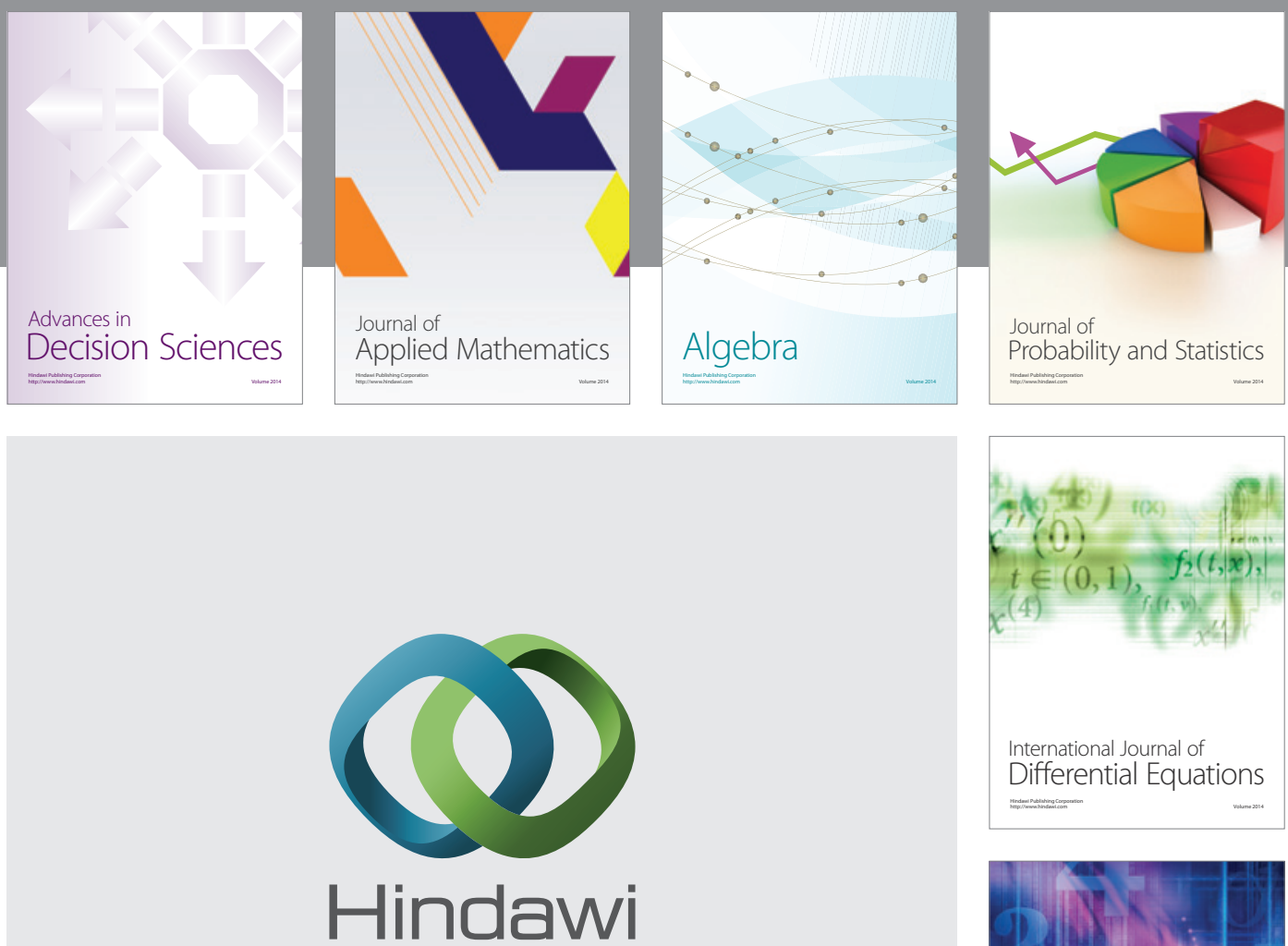

Submit your manuscripts at http://www.hindawi.com
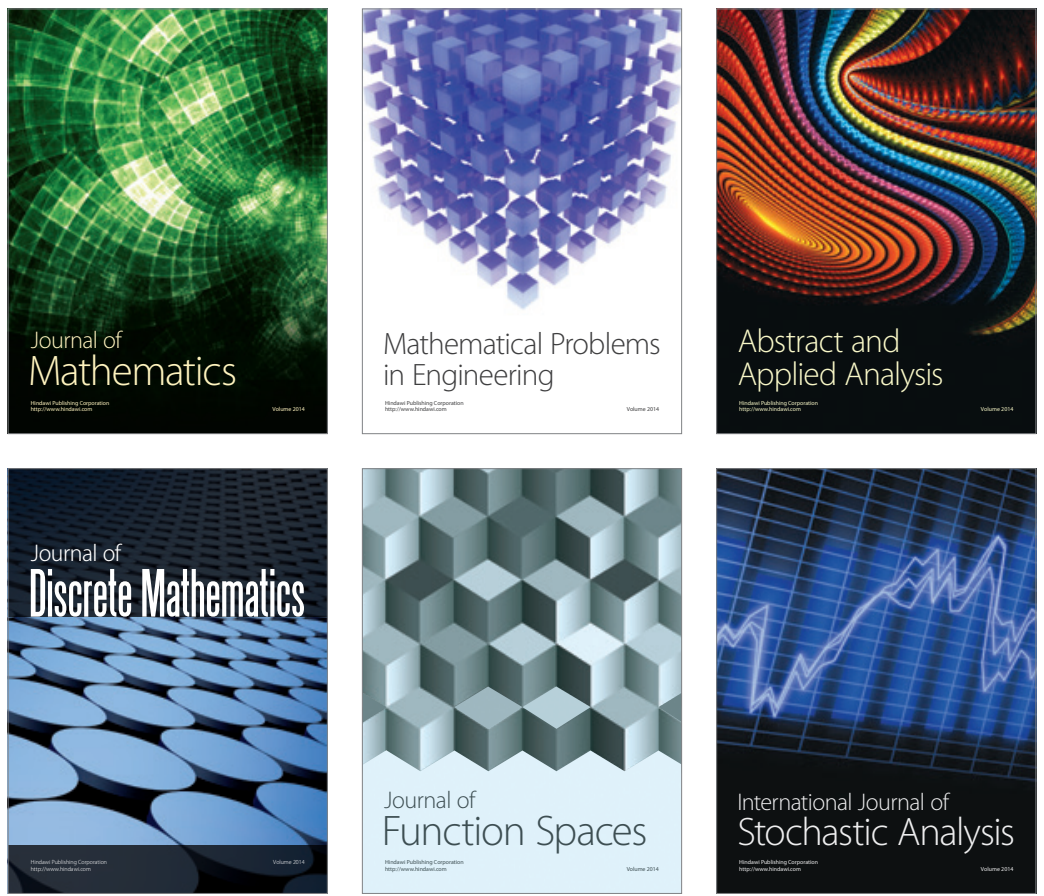

Journal of

Function Spaces

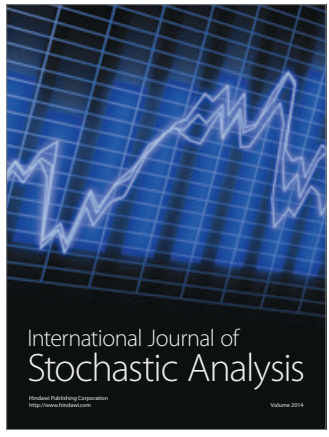

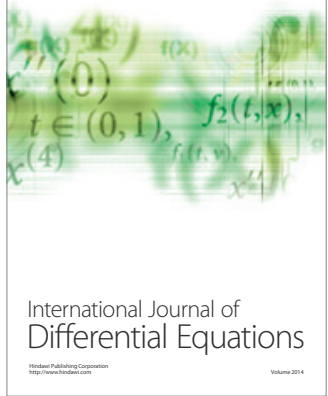
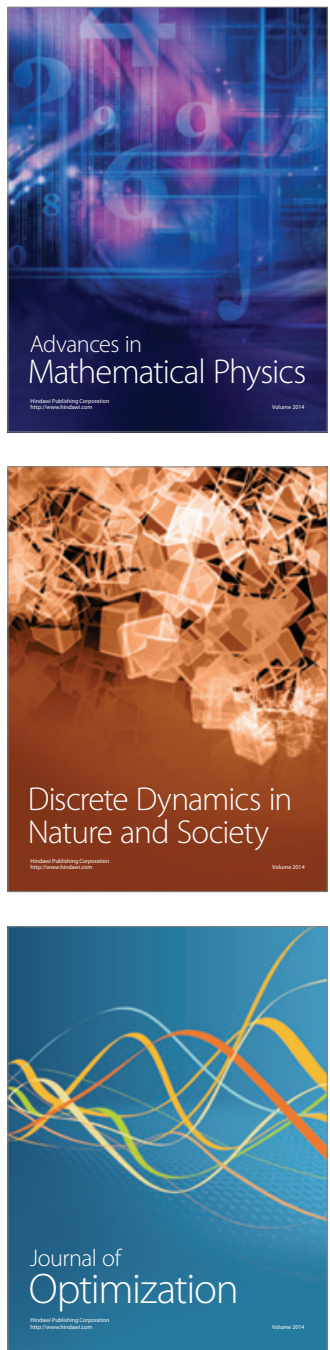